\title{
Exploring connectivity between spawning and nursery areas of Mullus barbatus (L., 1758) in the Mediterranean through a dispersal model
}

Francesco Gargano ${ }^{1,2^{*}}$, Germana Garofalo ${ }^{1}$, Fabio Fiorentino ${ }^{1}$,

${ }^{1}$ National Research Council (CNR) - Institute for Coastal Marine Environment

(IAMC) Via L. Vaccara, 61, 91026, Mazara del Vallo (TP), Italy

${ }^{2}$ Dept. Energy, Information and Mathematical Models (D.E.I.M), University of

Palermo, Italy

Corresponding author*: Francesco Gargano

Keywords: larval dispersal, red mullet, marine circulation model, Lagrangian transport, stock structure, metapopulation

\begin{abstract}
Connectivity between spawning and nursery areas plays a major role in determining the spatial structure of fish populations and the boundaries of stock units. Here, the potential effects of surface current on a red mullet population in the Central Mediterranean were simulated using a physical oceanographic model. Red mullet larvae were represented as Lagrangian drifters released in known spawning areas of the Strait of Sicily (SoS), which represents one of the most productive demersal fishing-grounds of the Mediterranean. To consider the effect of inter-annual variability of oceanographic patterns, numerical simulations were performed for the spawning seasons from 1999 to 2012. The main goal was to explore connectivity between population subunits, in terms of spawning and nursery areas, inhabiting the northern (SicilianMaltese) and southern (African) continental shelves of the SoS. The numerical simulations revealed a certain degree of connectivity between the Sicilian-Maltese and the African sides of the SoS. Connectivity is present in both directions, but it is stronger from the Sicilian-Maltese spawning areas to the African nurseries due to the marine circulation features of the region. However, because the majority of the larvae is transported to areas unsuitable for settlement or outside the SoS, the dispersal process is characterized by a strong loss of potential settlers born in the spawning areas. These results are in agreement with the low genetic heterogeneity reported for this species in the Mediterranean Sea and support the existence of a metapopulation structure of red mullet in the SoS and in the adjacent areas.
\end{abstract}

\section{Introduction}

Knowledge of connectivity patterns among marine populations is essential to understand the stock structure of fishery resources and to plan assessment and management strategies for their sustainable exploitation. The life cycle of many fishery resources is characterized by early life stages (eggs and larvae), transported from spawning to nursery areas by marine currents. Complex interactions between marine transport and environmental/biotic processes strongly influence the mortality rate in pre-recruitment stages, making this passive-dispersal phase critical.

(c) 2017 John Wiley \& Sons Ltd

Journal: Fisheries Oceanography

Gargano, F., Garofalo, G. and Fiorentino, F. (2017), Exploring connectivity between spawning and nursery areas of Mullus barbatus (L., 1758) in the Mediterranean through a dispersal model. Fish. Oceanogr., 26: 476-497. https://doi.org/10.1111/fog.12210 
The success of larval settlement, and subsequent recruitment strength, essentially depends on whether eggs and larvae are transported towards areas, generally close to coast, where environmental conditions match those required by the species to complete metamorphosis and recruit to the adult stock (see Cowen and Sponaugle, 2009 and reference therein).

The physical processes that control the dispersal of eggs and larvae from spawning areas to nurseries can connect very distant habitats and apparently isolated populations. Investigating the drift paths and the transport among Essential Fish Habitats (EFH; sensu Schmitten, 1999) is therefore of primary importance for estimating the degree of larval connectivity among local populations. Mixing of larvae driven into nurseries from spatially distinct spawning areas promotes the coexistence and connectivity of groups of populations with different demographic parameters (Roughgarden et al., 1988). This also favors gene flow and eventually affects the level of genetic heterogeneity. These mixing processes have allowed the development of the concept of metapopulation whereby the population parameters of different sub-units (e.g. recruitment, growth and mortality) may be driven predominantly by factors acting at the local level but with the existence of non-trivial replenishment of the sub-units' population through spawning and larval drift at the regional level (Kritzer \& Sale, 2004). This spatial structure is more complex than the classical "closed population" and is widely considered an important feature for the stability and persistence of a species (Hilborn et al., 2003; Kerr et al., 2010a,b). It enhances the resilience of a species in response to different environmental conditions and promotes the source-sink dynamics where populations producing high numbers of propagules (source) contribute to the replenishment of less productive populations (sink). Understanding the biological and environmental mechanisms leading to the spatial structure of populations is thus a key point in providing reliable resource assessment for appropriate and effective fishery management (Slatkin, 1993; Reiss et al., 2009; Goethel et al., 2011). Considering Mediterranean fisheries, small pelagic and demersal stocks are shared among fleets of different countries only in few areas (Lleonart and Maynou, 2003), including the Strait of Sicily (hereafter SoS), one of the most productive grounds for demersal fisheries (Fiorentino et al., 2008). Despite the importance of identifying appropriate fisheries management units, there are few studies addressing the issue of stock structure and stock boundaries in the Mediterranean (Fiorentino et al., 2015), accompanied by a general lack of knowledge regarding connectivity patterns (Di Franco et al. 2012, Calò et al., 2013).

The objective of this study is to perform numerical simulations of the dispersal of red mullet (Mullus barbatus, L. 1758) eggs and larvae to explore the connectivity between spawning and nursery areas in the SoS. The red mullet is one of the most valuable demersal species in Mediterranean sea and is subjected to high fishing pressure by bottom trawl and small scale fisheries (Fiorentini et al., 1997; Tserpes et al., 2002). The total mean annual yield of red mullet in the SoS amounted to ca. 640 ( \pm 150 s.d.) tonnes in the period 2009-2013 (Itafishstat source).

Our findings are discussed in relation to the possible red mullet metapopulation structure in the SoS. The presence of different red mullet stock units in this region has been widely debated in the past decades. Levi et al. (1992) found significant differences among red mullet growth parameters on the Sicilian side of the SoS and in the Gulf of Gabès. Furthermore, assuming the independence of water masses and the circulation system along the Sicilian and North African borders of the SoS, Levi et al. (1995) hypothesized the existence of distinct local stocks. On the basis of the occurrence of discrete spawning and nursery areas (Garofalo et al., 2004; Garofalo et al., 2008) distributed along the European and African shelves of the SoS, coupled with separate currents systems (Béranger et al., 2004), the existence of different sub-units of the red mullet population is considered highly probable (Fiorentino et al., 2008). A key point towards the verification of 
the above hypothesis is the determination of the connectivity pattern between the different spawning and recruitment areas previously outlined within the SoS.

Several methods can be used to investigate connectivity and dispersal processes in the marine environment. These methods were recently reviewed by Calò et al. (2013) and include the analysis of spatial distribution of eggs and larvae, genetics, otolith shape and microchemistry, tagging and tracking and dispersal models. In recent years, thanks to the increasing power of computing resources, numerical models solving geophysical fluid dynamics equations have been used to simulate the drift of eggs and larvae by treating them as Lagrangian particles driven by an oceanic circulation model (Kerr and Goethel, 2014). To date the few studies regarding larval dispersal between spawning and nursery areas through hydrodynamic models within the Mediterranean Sea are limited to European Anchovy (Engraulis encrasicolus). These studies concern the Western Mediterranean (Nicolle et al., 2009; Ospina Alvarez et al., 2012; Catalán et al., 2013), the Adriatic Sea (Sardone , 2011) and the Strait of Sicily (Bonanno et al., 2013; Palatella et al., 2014; Falcini et al, 2015). Within the Sardone Project larval dispersal of sardine (Sardina pilchardus) was also considered (Sardone, 2011).

In order to explore the connectivity between red mullet spawning and nursery areas in the south-central Mediterranean, we adopted the Lagrangian model used by Palatella et al. 2014 who investigated the dispersion of anchovy eggs and larvae in the SoS considering small scale vertical mixing. In particular we simulated the hydrological connectivity between known spawning areas and potential nurseries located over the Sicilian-Maltese and African shelves of the SoS over 14 years (1999-2012). The aim of these experiments was to analyze the larval supply from the spawning areas into the nurseries, as well as the spatio-temporal persistence of larval accumulation sites over the continental shelves bordering both the European and African coasts of the SoS.

\section{Materials and methods}

\subsection{The environmental characteristics of the study area}

The SoS connects the western and eastern Mediterranean and is characterized by a complex bottom topography (Figure 1). Along the southern coast of Sicily, the shelf is characterized by two wide and shallow banks in the western (Adventure Bank) and eastern (Malta Bank) sectors, separated by a narrow shelf in the middle. The North African shelf is very wide, especially along the Tunisian coasts. The northwestern side of the Tunisian coast is highly irregular with two shallow banks (the Galite and Skerki banks). In the Gulf of Gabès, the continental shelf extends far offshore and is characterized by shallow waters less than 30 $\mathrm{m}$ deep. The bathymetry deeper than $200 \mathrm{~m}$ on the western side of the SoS between Sicily and Tunisia is extremely irregular, whereas it is more regular to the East between Malta and Libya, with an average depth of less than $300 \mathrm{~m}$.

The currents in this region are mainly dictated by the Modified Atlantic Water (MAW) flowing eastward, and the Levantine intermediate Water (LIW) flowing westward along the Sicilian slope in the 200-500 m depth range. When the MAW hits the Sicilian coasts it bifurcates in two paths, one directed toward the Tyrrhenian sea, and the other directed toward the SoS. The latter splits in the Atlantic lonian Stream (AIS) along the south Sicilian coast and the Atlantic Tunisian Current (ATC) moving on the Tunisian continental slope (Béranger et al., 2004). Both the AIS and the ATC present significant seasonal variability owing to wind forcing and climate. Their effects are mainly appreciable in two different periods of the year: the AIS is more intense during the spring-summer period in the 15 - $30 \mathrm{~m}$ depth range, while the ATC is more pronounced in late autumn (Pinardi and Masetti, 2000; Sorgente et al., 2003; Sorgente et al., 2011). Since we are mainly interested in the transport and dispersion properties during the red mullet spawning period (May-July, Fiorentino et. al. 2008), the AIS is expected to have a stronger influence on this process than the 
ATC. Despite the strong annual variability, the AIS does exhibit some stability in circulation and hydrographic features (Figure 2). The main path of the AIS follows the Sicilian shelf edge along the Adventure Bank, it approaches the coast in the central area of southern Sicily and, when it meets the Malta Bank, it moves offshore into the lonian Sea (Sorgente et al., 2003; Pinardi et al., 2006). Along this path, the AIS circulates around two well-known large semi-permanent cyclonic vortices; the first one lying over the Adventure Bank (ABV) and the second over the Malta shelf (ISV), off Cape Passero (Figure 2).

\subsection{The life cycle of the red mullet}

Red mullet reproduction in the Strait of Sicily occurs almost exclusively from May to July with a peak in June (Fiorentino et al., 2008). Eggs, larvae and post-larvae up to $30-35 \mathrm{~mm}$ are restricted to surface waters (Montalenti, 1933; Sabatés and Palomera, 1987). In the Mediterranean Sea, larvae have been found mainly between June and July (Sabatés and Palomera, 1987; Zarrad et al., 2013).

Juveniles up to $4-5 \mathrm{~cm}$ total length (TL) are pelagic, have a blue livery and may be collected several miles offshore. Above this size (about $6 \mathrm{~cm} \mathrm{TL}$ ), juveniles move to coastal areas and spread out on sandy, muddy and gravelly bottoms to begin their demersal phase (Voliani, 1999). At settlement, their livery gradually changes from the juvenile to the adult colors (Voliani, 1999). Recent analyses have shown that the juvenile settlement of the red mullet in the Central Mediterranean occurs, on average, at 45 days of life, the presettlement stage starting after 30 days (Murenu et al., 2014, Matteo Murenu, pers. comm.).

As in other areas of the Mediterranean Sea, recruitment in the SoS occurs in shallow coastal waters in summer - early autumn (Levi et al., 2003).

Several papers have investigated the distribution of red mullet nursery and spawning areas in the northern continental shelf of the SoS (Sicilian-Maltese shelf). Overall, despite the presence of a certain interannual variability in the position, shape and intensity of hotspots of recruit and spawner abundance, the analysis of their spatio-temporal stability in the long term has revealed a well-defined pattern. In particular, although recruits have a widespread distribution over the sand-muddy bottoms up to 50-70 m depth, some areas characterized by high abundance and spatio-temporal persistence have been identified along the Sicilian southern coast (Garofalo et al., 2004; Garofalo et al., 2011). Regarding spawners, their distribution shows a high degree of spread across space and habitat (with preference for muddy substrates). The SicilianMaltese shelf is characterized by several persistent patches identified by mapping densities of spawners through GAM models over different years, and performing a persistence analysis on these density maps (Colloca et al., 2013). On the other hand, spawning grounds over the southern continental shelf of the SoS (African shelf) can be inferred by the distribution of the density hotspots determined through an inverse weighted interpolation by Garofalo et al. (2008) using one year (2003) of data.

On the basis of this knowledge, we consider the coastal areas having depth less than $60 \mathrm{~m}$ as potential nurseries, and those identified in the above quoted studies as spawning areas.

\subsection{The Lagrangian model}

Under the hypothesis that eggs and larvae are particles passively subjected to hydrographic forcing, we simulated larval transport with the Lagrangian model used by Palatella et al. (2014), which includes small scale turbulent mixing to increase the model's ability to mimic the chaotic behavior of the marine currents. Following is a brief introduction to the model; we refer the reader to the original paper for further details. To build the model, 3D current field time series in the Mediterranean Sea during the spawning period were 
obtained from the Mediterranean Sea Forecasting System (hereafter MFS; Tonani et al., 2008; Oddo et al., 2009), which is now part of the MyOcean Project (www.myocean.eu

www.gnoo.bo.ingv.it/mfs/myocean/description.html). This dataset, available since 1999, consists of daily means of the northward and eastward current velocity components $U_{\text {MFS }}=\left(u_{M F S}, v_{M F S}\right)$ on 72 unevenly vertical levels (ranging from $1.4 \mathrm{~m}$ to $5000 \mathrm{~m}$ depth), with a horizontal resolution of $1 / 16^{\circ} \times 1 / 16^{\circ}$ (ca. $7 \mathrm{~km}$ $\times 7 \mathrm{~km}$ ). As observed by Palatella et al. (2014), the horizontal resolution of $\boldsymbol{U}_{\text {MFS }}$ does not allow adequate resolution of the dynamics at scales smaller than the first internal Rossby radius of deformation, i.e. the horizontal scale at which the Earth rotation effect is comparable to the buoyancy and the important energy redistribution processes which occur in the mesoscale fields (Gill, 1982; Chelton et al., 1998; Saenko, 2006). In the period object of our investigation, the internal Rossby radius in the Mediterranean Sea varies in the 5 - $12 \mathrm{~km}$ range (see Grilli and Pinardi, 1998) and typically at least 2 grid points per radius are required to adequately resolve the eddy field. Hence, the spatial resolution of $\boldsymbol{U}_{\text {MFS }}$ is not adequate to resolve eddies at scales equal or smaller than the internal Rossby radius. To take the dynamics at such scales into account, Palatella et al. (2014) introduced an additional bi-dimensional velocity field $\boldsymbol{U}_{2 D}=\left(u_{2 D}, v_{2 D}\right)$, whose components are obtained from the stream function

$$
\Psi=\frac{A}{k} \sin [k(x-\varepsilon \sin (\omega t)] \sin [k(y-\varepsilon \sin (\omega t)]
$$

i.e. $\partial_{x} \Psi=v_{2 \mathrm{D}}$ and $\partial_{y} \Psi=-\mathrm{u}_{2 \mathrm{D}}$, where $A=0.1 \mathrm{~m} / \mathrm{s}, \varepsilon=0.1 I_{0}, \omega=2 \pi A_{0} / I_{0}$ and $k=2 \pi / I_{0}, I_{0}=20 \mathrm{~km}$ was chosen as it is twice the order of the first internal Rossby radius; $x$ and $y$ are the longitudinal and latitudinal coordinates, and $t$ is time. The effect of the superposition of the velocity field $\boldsymbol{U}_{2 D}$ induces some small scale disturbances which are variable in time, and this effect is visible in Figure 2, where the velocity

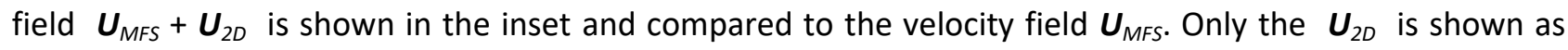
supplementary material (figure F4). Another limitation of $\boldsymbol{U}_{M F S}$ is that, being a 2D field on separate depth levels, it is unable to predict the chaotic vertical mixing due to small (order $10 \mathrm{~m}$ ) eddies characterizing the highly nonlinear dynamics of the Mediterranean basin (Pinardi and Masetti, 2000). To take this convective vertical mixing into account, a $3 D$ velocity field $U_{3 D}=\left(u_{3 D}, v_{3 D}, w_{3 D}\right)$ is also introduced and is obtained from the potential vector $\boldsymbol{\Phi}=\left(\Phi_{1}, \Phi_{2}\right)$ as $\partial_{z} \Phi_{1}=u_{3 D}, \partial_{z} \Phi_{2}=-v_{3 D},-\partial_{x} \Phi_{1}+\partial_{y} \Phi_{2}=w_{3 D}$. The components $\left(\Phi_{1}, \Phi_{2}\right)$ are defined according to

$$
\begin{gathered}
\Phi_{1}=\frac{A_{1}}{k_{1}} \sin \left[k _ { 1 } ( x - \varepsilon _ { 1 } \operatorname { s i n } ( \omega _ { 1 } t ) ] \operatorname { s i n } \left[k_{1}\left(z-\varepsilon_{1} \sin \left(\omega_{1} t\right)\right],\right.\right. \\
\Phi_{2}=\frac{A_{2}}{k_{2}} \sin \left[k _ { 2 } ( y - \varepsilon _ { 1 } \operatorname { s i n } ( \omega _ { 1 } t ) ] \operatorname { s i n } \left[k_{2}\left(z-\varepsilon_{2} \sin \left(\omega_{2} t\right)\right],\right.\right.
\end{gathered}
$$

where $A_{1}=0.036 \mathrm{~m} / \mathrm{s}, \varepsilon_{1}=0.2 I_{1}, \quad \omega_{1}=2 \pi A_{1} / I_{1}, \quad k_{1}=2 \pi / I_{1}, \quad A_{2}=0.041 \mathrm{~m} / \mathrm{s}, \quad \varepsilon_{2}=0.2 I_{2}, \omega_{2}=$ $2 \pi A_{2} / I_{2}, k_{2}=2 \pi / I_{2}$ where $I_{1}=30 \mathrm{~m} \mathrm{I}_{2}=42 \mathrm{~m}$ were chosen because twice the ideal order of the size of the small $3 \mathrm{D}$ eddies.

The time evolution of the Lagrangian particles is obtained by the system of equations

$$
\left\{\begin{array}{l}
\frac{d \mathrm{x}}{d t}=\mathrm{u}_{\mathrm{MFS}}(\mathbf{r}, \mathrm{t})+\mathrm{u}_{2 \mathrm{D}}\left(\mathbf{r}_{c}, \mathrm{t}\right)+\mathrm{u}_{3 \mathrm{D}}\left(\mathbf{r}_{c}, \mathrm{t}\right) \\
\frac{d \mathrm{y}}{d t}=\mathrm{v}_{\mathrm{MFS}}(\mathbf{r}, \mathrm{t})+\mathrm{v}_{2 \mathrm{D}}\left(\mathbf{r}_{c}, \mathrm{t}\right)+\mathrm{v}_{3 \mathrm{D}}\left(\mathbf{r}_{c}, \mathrm{t}\right) \\
\frac{d \mathrm{z}}{d t}=\mathrm{w}_{3 \mathrm{D}}\left(\mathbf{r}_{c}, \mathrm{t}\right)
\end{array}\right.
$$


where $r(t)=(x(t), y(t), z(t))$ is the position vector (longitude, latitude and depth), and $\mathbf{r}_{c}(t)=\left(x_{c}(t), y_{c}(t), z_{c}(t)\right)$ are relative coordinates computed in the reference frame of the mass center of two initially close particles in the so called quasi-Lagrangian approach. This allows to restore some well-known features in the dispersal process typical of turbulent flow (we refer the interested reader to the detailed discussions on this topic in Boffetta et al., 1999, Lacorata et al., 2008). Namely, if at a specific time $t$ a pair of initially closed particles have coordinates $\left(x_{1}(t), y_{1}(t), z_{1}(t)\right)$ and $\left(x_{2}(t), y_{2}(t), z_{2}(t)\right)$, then the relative coordinates of the particles are $\left(x_{i}(t)-x_{M}(t), y_{i}(t)-y_{M}(t), z_{i}(t)-z_{M}(t)\right)$, with $x_{M}(t)=\left(x_{1}(t)+x_{2}(t)\right) / 2, y_{M}(t)=\left(y_{1}(t)+y_{2}(t)\right) / 2, z_{M}(t)=$ $\left(z_{1}(t)+z_{2}(t)\right) / 2$ being the coordinates of the mass center of the two particles. This approach is based on the assumption that each pair of initially closed particles moves in its own kinematic field anchored to its mass

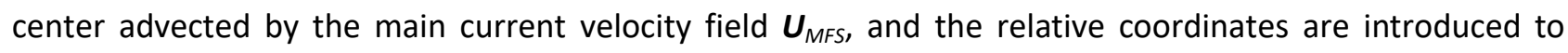
account for the small scale dispersion of the vortex-like structures induced by the velocity field $\boldsymbol{U}_{2 D}$ and $\boldsymbol{U}_{3 D}$. Since the larvae of Mullidae are generally found in the surface 10 meters water (Sabatés and Palomera, 1987; Olivar and Sabatés, 1997), the effect of vertical migration of the larvae was not considered.

Both the velocity fields $\boldsymbol{U}_{2 D}$ and $\boldsymbol{U}_{3 D}$ define an incompressible flow and reproduce, respectively, non-steady 2D and 3D lattice of vortices. They are mainly introduced to allow for the typical short time and small spatial scale variability in the dispersive transport, an effect which is impossible to reproduce with the spatially and temporally coarser resolution of $\boldsymbol{U}_{\text {MFS }}$ alone. The introduction of the velocity fields $\boldsymbol{U}_{2 D}$ and $\boldsymbol{U}_{3 D}$ clearly can only partially simulate and restore the real spatio-temporal small-scale variability of some features of the chaotic marine currents and should only be considered a starting model to mimic these effects. We therefore stress that our result should be considered as highly qualitative and representing the characteristics of the larval transport at a large scale. Nevertheless, Palatella et al. (2014) proved the reliability of the model by performing an analysis on the root mean square separation between the real trajectory of experimental drifters obtained from the ARGO program (http://www.ifremer.fr/) and the numerical simulation, showing the good predictive behavior of the model up to the intrinsic chaoticity of the marine current dynamics. Furthermore, Lacorata et. al. 2014 calibrated the $\boldsymbol{U}_{2 D}$ field to reduce the errors between real Mediterranean drifter data and Lagrangian numerical data, and they introduced more modes inducing different scales in the superimposed velocity field; the experiments finally demonstrate that the addition of the velocity field $\boldsymbol{U}_{2 D}$ allows, in part, to recover the error due to the unresolved scales of the velocity field $\boldsymbol{U}_{\text {MFS }}$ within the Mediterranean sea. In the appendix we explore in detail how particle motions and results are influenced by the superposition the $\boldsymbol{U}_{2 D}$ and $\boldsymbol{U}_{3 D}$ fields, and also by the variability of the parameters defining these fields.

\subsection{The initial setup}

Different numerical experiments were implemented to track larval trajectories from the spawning areas up to their aggregation into potential nurseries or their dispersal outside the study area. We ran simulations over a 14 year time-period from 1999 to 2012.

In the scenario considered, eggs were equally distributed within the Sicilian-Maltese and African spawning areas, denoted as $\mathrm{Zm1-Zm7}$ and $\mathrm{Zm8-Zm14}$ respectively (Figure 3), to examine connectivity between the northern and southern continental shelves of the SoS in terms of larval supply to potential nurseries in the investigated area. Zones Zm1-Zm14 were centered where spawning sites are located according to previous studies carried out in the SoS (Garofalo et al., 2004; Garofalo et al., 2008; Colloca et al., 2013). Potential nursery areas were identified as the Sicilian, Maltese and African coastal areas, hereafter denoted as SN, $\mathrm{MN}$ and AN, respectively (Figure 3). The boundaries of the potential nursery areas were obtained by 
extracting the $60 \mathrm{~m}$ bathymetric contour levels from the ETOPO1 1 Arc-Minute Global Relief Model provided by the Geodas Grid Translator of the National Geophysical Data Center (NOAA - available online at: www.ngdc.noaa.gov/mgg/global/global.html).

Each annual set of simulations produced trajectories from May 1 to July 31 . Each day we placed $N$ drifting particles (i.e. eggs) in the spawning areas, with a maximum $N_{0}$ eggs released and held constant from $1^{\text {st }}$ to $30^{\text {th }}$ June; $N$ was then decreased in May and July according to the law $N=N_{0} \cdot \mathrm{e}^{-\left(\frac{d}{15}\right)^{2}}$, where $d$ is the time lapse, in days, between a given day of May and June 1 or a given day of July and June 30 .

A total of 800 particles for each day of June were equally distributed among spawning areas Zm1-Zm14 (Figure 3) schematized as equally-sized rectangles following appropriate bathymetric levels. The particles were randomly located within each spawning area, and the minimum number of eggs in each area was set to 8 in May and July. The total number of particles released in the whole period 1999-2012 was 634872 .

As we were mainly interested in the dispersal effect due to the marine currents, we did not take the mortality of the eggs/larvae into account, and we followed their trajectories up to 45 days from their initial release. The particles were randomly released at a depth between $3 \mathrm{~m}$ and $10 \mathrm{~m}$ and they were driven by the velocity field introduced in the previous section. The numerical solutions of the Lagrangian system were obtained by using the well-known fourth order Runge-Kutta temporal scheme (Lambert and Lambert, 1991) with a time step of $d t=120 \mathrm{~s}$. As the velocity field $\boldsymbol{U}_{\text {MFS }}$ is given on the model's spatial grid each day, in order to recover the exact value $\boldsymbol{U}_{\text {MFS }}(\boldsymbol{r}(t))$ in $\boldsymbol{r}(t)$ not necessarily coinciding with a grid point, velocity was bilinearly interpolated horizontally between the nine grid cells surrounding the position $(x(t), y(t))$ and linearly interpolated vertically between the two depth levels bounding $z(t)$ at each time step. To avoid a temporal discontinuity in the evaluation at 12:00 PM when passing from a day to another, $\boldsymbol{U}_{M F S}$ was linearly weighted between two consecutive days from 08:00 PM to 12:00 PM so that the velocity field of a specific day smoothly changed to that of the following day. Finally, if a particle was driven to the coast, it rebounded to the previous position, by means of a reflective boundary condition imposed along the basin boundaries.

\subsection{Larval transport success and hotspot analysis}

The simulated positions of the larvae were used both to estimate the larval fraction arriving in nursery areas each year, hereafter "transport success" (TS), and its complement, i.e. the fraction lost to the open sea (hereafter "larval fraction lost"). Moreover, by means of a hotspot analysis of the larval abundance index, we searched for coastal patches where larvae concentrate (hotspots) during their settlement phase. The TS was computed for each year following the same procedure employed for instance in Huret et. al. 2007 for determining the TS of the early stages of the cod in the western Gulf of Maine. In particular, the TS was defined as the percentage of time that a larva spends over the nursery when capable of bottom settlement. In our case, given that pre-settlement and settlement stages occur on average at 30 and 45 days, respectively, the TS of a larva was evaluated as the proportion (value in the range $[0,1]$ ) of the total number of days it spent over a nursery during the time range 30-45 days (actually we check for the position of a larva every six hours to obtain a more refined result). After having computed the TS for all larvae, we computed the global TS following simple statistical arguments. In particular, if $\mathrm{TS}_{j, Z}^{i, N u r s}$ is the TS over a nursery of the generic larva $i$ initially released in a specific zone $Z$ (i.e. one of $Z m 1-Z m 14$ ) in the year $j$, the TS in $\mathrm{SN}, \mathrm{MN}$, AN were simply computed as:

$r_{j, Z}^{S N}=\sum_{i}^{\mathrm{TS}_{j, Z}^{i, S N}} / N_{Z}^{i n}, r_{j, Z}^{M N}=\sum^{\sum_{i} \mathrm{TS}_{j, Z}^{i, M N}} / N_{Z}^{i n}, r_{j, Z}^{A N}={ }^{\sum_{i} \mathrm{TS}_{j, Z}^{i, A N}} / N_{Z}^{i n}$, 
where $N_{Z}^{i n}$ is the total number of larvae released in zone $Z$ in year $j$. The annual larval fraction lost, i.e. the larvae not arriving in any of the potential nurseries within the SoS, was computed as $r_{j, Z}^{\text {loss }}=1-\left(r_{j, Z}^{S N}+\right.$ $\left.r_{j, Z}^{M N}+r_{j, Z}^{A N}\right)$.

The mean transport successes $\bar{r}_{Z}^{S N}, \bar{r}_{Z}^{M N}, \bar{r}_{Z}^{A N}$ and the mean larval fraction lost $\bar{r}_{Z}^{\text {loss }}$ with the relative standard deviations were calculated throughout the period 1999-2012. We also defined a measure of the connectivity between the two sides of the SoS by considering the sum of the TS of the eggs released in the Sicilian-Maltese spawning areas and arriving into the $\mathrm{AN}, c_{j}^{A N}=r_{j, Z m 1}^{A N}+\cdots r_{j, Z m 7}^{A N}$, and the sum of the TS of the eggs released in the African spawning areas arriving into $\mathrm{SN}$ and $\mathrm{MN}, c_{j}^{S N}=r_{j, Z m 8}^{S N}+\cdots r_{j, Z m 14}^{S N}, c_{j}^{M N}=$ $r_{j, Z m 8}^{M N}+\cdots r_{j, Z m 14}^{M N}$.

Regarding the determination of the spatial patches within the potential nurseries SN, MN and AN, that are expected to be rich of settlers, we performed a hotspot analysis to quantify the temporal and spatial variance of larval abundance. The region $\Omega=\left[7^{\circ} \mathrm{E}, 20^{\circ} \mathrm{E}\right] \times\left[30^{\circ} \mathrm{N}, 40^{\circ} \mathrm{N}\right]$ was chosen by ensuring that it contained all the final positions of the larvae in the study area. Region $\Omega$ was divided in $1 / 16^{\circ} \times 1 / 16^{\circ}$ cells, giving a total of 21160 cells with the exception of the inland cells. The total number of larvae within each cell during their last 16 days of transport was counted, obtaining the larval abundance index (Al). Hence, the Getis and Ord gi*- analysis (Getis and Ord, 1992; Ord and Getis, 1995) was applied to identify the larval hotspots in region $\Omega$ through the analysis of the z-score (or $\mathrm{p}$-level) values. The z-score value in each cell was determined by averaging the 8 neighboring cells. The cells showing a z-score greater than a given threshold value were marked as hotspots. The selection of this threshold inevitably added some degree of arbitrariness that we have tried to limit according to the characteristics of the data. We observed that for each year the Al was generally rich with zeros or very small values (quasi-zero inflated problem), meaning that the mean value $M_{\Omega}$ of the Al was a small number. Choosing a small threshold leaded to marking a large and unrealistic number of cells as hotspots, because cells having moderate-small numbers of larvae were also considered significantly above the mean $M_{\Omega}$. Increasing the threshold value solved this issue. After several trials, the threshold value of 7 was considered optimal to filter the cells where a large part of the larvae were highly concentrated. Once we marked the hotspot cells in each year, we computed the ratio of the years in which a cell is an hotspot to the total years, obtaining a value between 0 and 1 for each cell that can be interpreted as a persistence index $(\mathrm{PI} *)$. For example, a $\mathrm{PI}^{*}=1$ for a given cell means that in all years that cell is a hotspot ( $\mathrm{Al}>$ threshold) and therefore can also be considered a persistent hotspot.

To validate the result obtained in the above analysis we also performed an alternative hotspot analysis, according to Santora and Vetit (2013). We first computed the mean value $M_{\Omega}$ and the standard deviation $\sigma_{\Omega}$ of the Al in region $\Omega$ for each year; then, in each cell, we checked if the local Al exceeds the mean value $M_{\Omega}$ by $\alpha \cdot \sigma_{\Omega}, \alpha$ being a positive real value. By increasing $\alpha$ we search for Al values that are sufficiently large and far from $M_{\Omega}$, and this serves as a filter for detecting abundance peaks (hotspots). Again, the choice of $\alpha$ inevitably requires some degree of arbitrariness, and the value $\alpha=4$ was considered optimal for our case. The persistence index (PI) of the hotspot cell was then obtained in the same manner as for $\mathrm{PI}^{*}$.

\section{Results}

\subsection{Larval dispersion and connectivity between the Sicilian-Maltese and African shelves}

The numerical simulations performed for the scenario presented in Figure 3 allowed us to track larval transport between the northern and southern sides of the SoS. Figures 4 and 5 show the average trajectories of eggs released in Zm1-Zm14 in 2004 and 2008, respectively. These years were selected because they incorporate most of the dynamical patterns observed in the entire period 1999-2012. For instance, concerning the African spawning zones, the connectivity with the SN is typically represented by 
trajectories starting from $\mathrm{Z9}$ and $\mathrm{Z} 10$ and arriving in the southwestern coast of the Sicily (Figures 4-5). Other recurrent patterns result in trajectories starting from Z8, Z11, Z12, Z13 and arriving in the Gulfs of Hammamet and Gabès. Conversely, the majority of the patterns related to the connectivity between the Sicilian spawning areas and the AN are represented by trajectories starting from Z1,Z5 (Figure 4), Z3,Z4,Z7 (Figure 5) and arriving in the Gulf of Gabés and in the Gulf of Sidra respectively. Further recurrent patterns for Sicilian spawning zones are trajectories starting from Z1,Z2,Z3,Z5 (Figure 4-5) and remaining in the northern part of the SoS.

Although an average of the trajectories inevitably removes some small-scale patterns, these averages capture most of the typical dynamical behaviors observed in the larval transport process.

Analysis of larval dispersal pattern indicates a wide larval dispersion with high larval fraction lost from all SoS spawning areas.

Among the zones of the northern side of the SoS, $\mathrm{Zm} 1$ and $\mathrm{Zm} 2$ have the highest $T S, Z m 2$ being also characterized by a strong inter-annual variability, as one can infer by the high standard deviation (Table 1). In particular, the fraction of larvae lost from Zm2 varies from a minimum value of 0.56 in 2001 to 0.99 in 2008 and 2010 (see annual rates provided as supplementary material T1). The other zones on the SicilianMaltese shelf have large means of the larval fraction lost with weak to moderate variability. With the exception of Zm14 (off Linosa), the African spawning areas have higher mean TS than the Sicilian-Maltese ones, $\mathrm{Zm} 8$ and $\mathrm{Zm} 12$ showing the highest TS among African zones.

Regarding the connectivity between the two shelves, we can infer that the AN is weakly supplied by the Sicilian-Maltese spawning areas $\left(\bar{r}_{Z}^{S N}\right.$, mainly in the range $\left.0.0001-0.0006\right)$ with the exception of Zm5 (the closest to the African coast) showing an average value $\overline{\boldsymbol{r}}_{Z m 5}^{S N}=0.026$ (Table 1). The larval supply from the African spawning areas towards the Sicilian-Maltese nurseries is also weak, with Zm9, Zm10 and Zm14 supplying more larvae to the Sicilian-Maltese shelf $\left(\overline{\boldsymbol{r}}_{Z \boldsymbol{m} \mathbf{9}}^{S N}=0.0034, \overline{\boldsymbol{r}}_{\mathbf{Z m 1 0}}^{S N}=0.0033, \overline{\boldsymbol{r}}_{\mathbf{Z m 1 4}}^{S N}=0.0008\right)$. Figure 6 provides a more synthetic way to understand the degree of connectivity between the two sides of the SoS, showing the sources of the various nurseries in the period 1999-2012. The SN is mainly supplied by the Sicilian spawning areas $Z m 1, Z m 2, Z m 3$ and weakly supplied by $Z m 4, Z m 5, Z m 9, Z m 10$. MN is mainly supplied by the Maltese area $\mathrm{Zm6}$, with a moderate contribution of $\mathrm{Zm2}, \mathrm{Zm7}, \mathrm{Zm} 14$. The AN is mostly supplied by the African spawning areas, $Z m 8$ and $Z m 12$ especially. It is worth noting that the Sicilian spawning areas $\mathrm{Zm} 1$ and $\mathrm{Zm} 3$ as well as the Maltese $\mathrm{Zm} 6$ and the African $\mathrm{Zm} 8$ show a strong local retention of eggs and larvae.

Considering the sum of the TS of eggs released in all the Sicilian-Maltese spawning areas reaching the AN in year $j\left(\boldsymbol{c}_{j}^{A N}\right)$ and that of eggs released in all the African spawning areas reaching the SN and MN $\left(\boldsymbol{c}_{\boldsymbol{j}}^{\boldsymbol{S} N}+\boldsymbol{c}_{\boldsymbol{j}}^{\boldsymbol{M N}}\right)$, the overall connectivity between the Sicilian-Maltese spawning areas and the AN is more supported by the dispersal process, with the exception of 2004, 2006, 2009 and 2010, when transport from African spawning areas to SN/MN was higher (Figure 7).

\subsection{Larval dispersion and identification of settlers hotspots}

The final distribution of larvae at the end of the dispersal period was used to estimate areas where settlers are highly and stably concentrated.

The distribution of the persistence index $\mathrm{PI}^{*}$ in region $\Omega$ (related to the Getis and Ord gi*-hotspot analysis) is shown in Figure 8. Three main persistent hotspots of settlers can be identified in the SoS. The first hotspot, $\mathrm{Ns}^{*}$, with $\mathrm{PI}^{*}$ values close to 1 , is a wide zone located within the SN. It extends from the southwestern corner of Sicily close to Mazara del Vallo to the Gulf of Gela (see Figure 1 ) with a main core close to the coast off Sciacca. The second hotspot $\mathrm{Nm}^{*}$ is smaller and is placed close to southeastern Malta but marginally within the MN. The third hotspot Na1* is found in the shallow waters (AN) north of 
the Gulf of Hammamet. Since the two hotspot analysis procedures gave very similar results overall, we present the PI distribution as supplementary material (F1).

\subsection{Discussion}

Overall, the simulation of larval dispersal showed a low level of connectivity between the Sicilian-Maltese and the African population subunits together with a substantial larval fraction lost outside the investigated area. This weak connectivity occurs in both directions but, due to the marine circulation features of the region, exchange is stronger from the Sicilian-Maltese spawning areas to the African nurseries. These findings are consistent with the regional-scale 'ocean triad' identified in the SoS by Agostini \& Bakun (2002). According to the authors, the prevailing westerly winds over the SoS, induce the transport of surface waters (Ekman transport field) from upwelling (nutrient enrichment) areas occurring along the southern coast of Sicily toward the eastern coast of Tunisia where convergence and downwelling (concentration and retention) occurs.

The different zones of egg release considered in our simulations are characterized by different hydrological features, which appear to markedly influence larval transport. Indeed, in the time span of 45 days of larval drift, patterns of local retention or dispersion over long distances are observed depending on the location of the spawning area.

Considering the scenario proposed for the experiments, only eggs released along the northwestern coast of Tunisia are driven towards the Sicilian and Maltese coasts by surface currents (Sorgente et al., 2011). Spawning zones west of Linosa are connected to the $\mathrm{SN}$ and $\mathrm{MN}$ in those years when the current pattern around Linosa can catch larvae driving them towards the AIS path and ultimately the SN. The weak and variable circulation pattern observed close the African coasts (Sorgente et al., 2011) makes the connectivity between the other African spawning areas and the SN/MN very weak or absent. Consequently, the majority of eggs released in African spawning areas are generally confined close to the African coasts during their drift. Regarding the Sicilian-Maltese shelf, only the spawning area located far off the southwestern coast of Sicily, over the Adventure Bank, seems to supply settlers to the potential nurseries in the Gulfs of Hammamet and Gabès, while eggs initially released in the area far off the eastern coast of Malta can drift towards the Gulf of Sidra. On the other hand, the connectivity between the other Sicilian-Maltese spawning areas and the AN is in general very weak.

Retention processes were also observed in our experiments. The eggs released in the coastal spawning areas of the Sicilian-Maltese continental shelf (southwestern and southeastern coast of Sicily and eastern coast of Malta) are retained into the SN and MN respectively. Larvae born along the southwestern coast of Sicily are partially driven by the velocity field induced by the semi-permanent vortex ABV that retains most of them close to the natal area. We can schematize the above results as shown in Figure 9 where the main spawning areas are shown, with those which are close and similar in dispersal patterns aggregating in larger reproductive spatial structures. Arrows schematise movements from spawning to nursery areas. The width of the arrows increases with the larval transport success in the various nurseries (see Table 1). It is worth noting that, with the exception of the spawning areas located in the north and in the middle part of the SoS, most of the reproductive subunits distributed along the European and African shelves can be considered self-recruiting populations.

The hot-spot analysis suggests that the main areas suitable for juvenile settlement are in southwestern Sicily, along the southeastern coast of Malta and in the shallow water north of the Gulf of Hammamet. Although the shape (and the position) of the spawning areas inevitably influences the final results, some 
spatio-temporal characteristics of these patches seem to be independent of the shape of the initial spawning areas. To check for the dependence of this patch on the initial spawning areas, we performed alternative simulations by slightly changing the shape, the orientation and the position of the spawning areas and essentially obtained the same results.

It is worth noting that the distribution of the persistent areas of settler concentrations derived from this model agree quite well with the field knowledge on established nurseries of red mullet along the southern coast of Sicily (Garofalo et al., 2011). These established nurseries refer to areas where the young of the year, about 90-120 days old, have concentrated stably throughout years. On the contrary, the hotspot of settlers refers to areas where small fry, $c a .45$ days old, aggregate at settlement. The good overlap between the two critical areas suggests that the same habitat is used from settlement to the first months of benthic life. However, it is worth noting that, in the case of Ns1*, the surface occupied by the settler hotspot is greater than that covered by the established nursery. Aside from the dependence on the choice of the threshold used in the hotspot analysis, the difference could be due to an active migration of the young recruits towards more coastal and suitable habitats after settlement. However, these slight differences could be due to the fact that, because of the limited information on the larval phase of red mullet, our model does not consider growth mortality nor proper vertical migration of larvae. Comparing simple Lagrangian (passive) transport and biological behavior transport, including egg-buoyancy, larval growth, and diel vertical migrations in anchovy of North-western Mediterranean, some differences in dispersion of larvae were found by Ospina-Alvarez et al., (2012). In particular, eggs and larvae were less clustered in the passive transport experiment and areas where post-larvae arrived at the end of the dispersal phase were larger than those resulting from biological behavior transport. A remarkable result of our simulation experiments is that the larval drifting process is generally characterized by a strong loss of larvae. Indeed most of them do not reach a potential nursery at the end of the larval stage or are transported away from the potential nurseries in the SoS. It is difficult to hypothesize something about the fate of these presettlers. The negative effect of the offshore transport on fish recruitment was recently remarked by Nieto et al. (2014) in Sardine off California (Pacific Ocean), because this advection to the open ocean contrasts the return of juveniles to in-shore waters where they are known to recruit. Recently, Falcini et al. (2015), studying the anchovy in the SoS, reported that intense upwelling due to strong northwesterly mistral winds combined with topographic effects reduces the advection of eggs and larvae to the coastal nurseries off the southeastern coast of Sicily. However, we think that in a semi-enclosed sea, such as the Mediterranean, the probability that eggs and larvae transported offshore by currents, can reach suitable coastal areas even far from their natal area should be higher than in the Oceans. Furthermore, since the settling stages of fish species can delay metamorphosis until they reach a habitat suitable for settlement (McCormick, 1999; Bradbury and Snelgrove, 2001), the possibility that some larvae born in the spawning areas of the SoS can recruit on nurseries of other Mediterranean subareas should not be discarded.

It is well known that the greatest contribution to genetic exchanges in marine organisms comes from dispersal pelagic stages (Pineda et al., 2007; Cowen and Sponaugle, 2009; Schunter et al., 2011), and the high dispersal of larvae we found in the SoS can partially explain the low genetic heterogeneity which characterizes the red mullet in the Mediterranean.

On the basis of microsatellite analyses, Maggio et al. 2009 found a clear isolation only in the Adriatic Sea red mullet population, whereas a weaker sub-structuring of the populations resulted in the Gulf of Lions, Tyrrhenian Sea, Strait of Sicily, and Ionian Sea. Galarza et al. 2009, working with microsatellite loci on samples from the Alboran Sea, Catalan Sea, Balearic Islands, Ligurian Sea, Southern Tyrrhenian Sea, Ionian Sea and Levantine basin, reported a red mullet metapopulation structure composed by independent, selfrecruiting subpopulations with some connections between them. It is worth noting that no apparent differences were found between the Southern Tyrrhenian and Ionian populations, suggesting that 
spawners reproducing in these areas belong to a common genetic pool. More recently, Felix-Hackradt et al. (2013) reported a high genetic homogeneity for red mullet along the Mediterranean Spanish coast, from the Alboran Sea to the Catalan Sea. In the red mullet case, the maintenance of this low genetic heterogeneity in Mediterranean populations could be due to the occurrence of a high dispersal phase coupled with a reproductive behavior in which organisms spawn in the spawning areas closest to their nursery grounds (Heath et al., 2008; Kerr and Goethel, 2014).

Considering that red mullet lives in waters shallower than $300 \mathrm{~m}$ and that the presence of deep waters creates a natural barrier between the Sicilian and African shelves, the hypothesis that larvae born on one side of the Strait may settle in a nursery on the other side and come back to natal spawning areas (natal homing) for reproduction seems improbable. In conclusion, the patterns of simulated eggs and larvae drift strongly support the assumption of the existence of a metapopulation structure sensu Kritzer \& Sale (2004) for red mullet in the SoS, formed by the spawning subunits located on the Sicilian-Maltese shelf which show a weak connectivity with the African shelf subunits. This vision of the spatial structure of the species in the area is compatible with the assumption of a Sicilian shelf stock unit for red mullet, adopted by Levi et al. (2003) in investigating the spawning stock recruitment relationship (SSRR) including oceanographic anomalies. However, the high larval fraction lost outside the investigated area, together with the weak and variable connectivity between the Sicilian and African population subunits, could explain that part of the variability in recruitment strength, estimated by SSRR, which is not explained by both spawner abundance and anomalies in oceanographic pattern.

This study represents a first step towards the understanding of the population structure of an important demersal resource in the SoS based on a simple simulation of Lagrangian connectivity between spawning and nursery areas. We integrated the available information on the ecology of reproduction, settlement and recruitment the species. However, many factors other than passive larval dispersal by ocean currents (e.g. larval mortality, food availability, water temperature, vertical larval migrations; Sabates et al., 2007; Somarakis and Nikolioudakis, 2007; Nicolle et al., 2009; Ospina-Alvarez et al., 2012; Bonanno et al., 2013), could affect the successful settlement of larvae in habitats suitable to the completion of metamorphosis and recruitment to the adult stock.

Improving our knowledge on dynamics and behavior of the pre-recruitment phases of the red mullet life cycle will allow us to increase the reliability of the dispersal models and the understanding of the relationships between essential fish habitats and population structures of this important target species of Mediterranean fisheries.

\section{Appendix}

In this Appendix we carry out a sensitivity analysis aimed at investigating the effects of including the velocity fields $\boldsymbol{U}_{2 D}$ and $\boldsymbol{U}_{3 D}$ defined Section 2.3, and of varying some of their main parameters. In particular, we have considered years $(2004,2008,2011)$, and performed several experiments to determine the influence of the fields $\boldsymbol{U}_{2 D}$ and $\boldsymbol{U}_{3 D}$ on the TS. Years 2004 and 2008 were considered relevant because they incorporate most of the dynamical patterns observed in the entire period 1999-2012 (see Figures 4 and 5 and the discussion in Section 3.1), while 2011 was considered because it shows the highest difference between Sicilian/African and African/Sicilian connection rates (see Figure 7)

The main experiment was aimed at determining the effects of the superposition of the fields $\boldsymbol{U}_{2 D}$ and $\boldsymbol{U}_{3 D}$ on

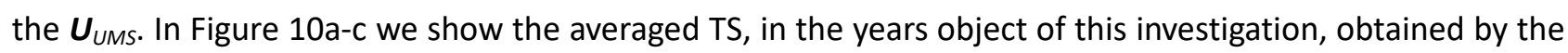
following four experiments: $\boldsymbol{U}_{U M S}+\boldsymbol{U}_{2 D}+\boldsymbol{U}_{3 D}$ (results already presented in Section 3), $\boldsymbol{U}_{U M S}, \boldsymbol{U}_{U M S}+\boldsymbol{U}_{2 D}$, and $\boldsymbol{U}_{\text {UMS }}+\boldsymbol{U}_{3 D}$. 
Despite some obvious differences in the quantitative results, the main features of the various zones, in terms of TS, were maintained in all the cases considered. Regarding the TS of the SN, among the zones of the northern side of the SoS, $\mathrm{Zm1}, \mathrm{Zm} 2$ and $\mathrm{Zm} 3$ are those with the highest TS. The relevant differences appear mainly in the case of the $\boldsymbol{U}_{\text {UMS }}$ only. In fact, while the TSR of Zm1 increases in the SN, the TS of Zm2 and $Z \mathrm{~m} 3$ decreases in the SN. This is likely due to the high intensity of the AIS in the first $20 \mathrm{~m}$ depth, where the particles are released. Without the vertical transport induced by the $\boldsymbol{U}_{3 D}$ field, the larvae released in $\mathrm{Zm1}$, and not retained close this zone, are more easily transported in the south-eastern part of the SN, while those in $\mathrm{Zm} 2$ and $\mathrm{Zm} 3$ are more easily transported outside the SN. Adding the 2D velocity field (the case $\boldsymbol{U}_{U M S}+\boldsymbol{U}_{2 D}$ ) in part restores retention of the particles within the $S N$, while in the case $\boldsymbol{U}_{U M S}+\boldsymbol{U}_{3 D}$ we have essentially obtained the same results observed in the case $\boldsymbol{U}_{\text {UMS }}+\boldsymbol{U}_{2 D}+\boldsymbol{U}_{3 D}$. In Figures 15 and 16, selected 45 -days particle-paths starting from $Z \mathrm{Zm} 1$ and $\mathrm{Zm} 2$ respectively, with particles released in the same day and same positions, are shown for each of the cases considered. The particles released in $\mathrm{Zm} 1$ are transported outside the SoS in the case $U_{U M S}$ and $U_{U M S}+U_{2 D}$, due to the intense current, while in the other cases the vertical mixing due to $\boldsymbol{U}_{3 D}$ induces a particle motion which is always confined to remain close the Sicilian coastal area. Snapshots of the positions of selected particles initially released in Zm1-Zm3, are shown at 15, 30 and 45 days in the supplementary material (Figure F2).

More variability in TS is observed for the MN. Although Zm1, Zm2 and Zm6 always have the highest TS for the $M N$, the inclusion of the $\boldsymbol{U}_{2 D}$ and/or $\boldsymbol{U}_{3 D}$ highly influences the final results, e.g. removing the $\boldsymbol{U}_{2 D}$ field results in an significant increase for the TS of zones $\mathrm{Zm1}$ and $\mathrm{Zm} 2$, while that of $\mathrm{Zm} 6$ is almost halved.

In the southern part of the SoS, the TS of zones Zm8-Zm14 for the AN is maintained quite high in all cases. As previously observed in the case of the TS in the $\mathrm{SN}$, there are no relevant differences between the $\boldsymbol{U}_{\text {UMS }}+$ $\boldsymbol{U}_{2 D}+\boldsymbol{U}_{3 D}$ and $\boldsymbol{U}_{U M S}+\boldsymbol{U}_{3 D}$ cases, while removing the $\boldsymbol{U}_{3 D}$ field in $\boldsymbol{U}_{U M S}$ and $\boldsymbol{U}_{U M S}+\boldsymbol{U}_{2 D}$ increases the TS in the $\mathrm{AN}$, favouring the retention of particles in this zone. A possible explanation of this phenomenon can be given again in terms of the hydrographic features of the African coasts. Here the weak and variable circulation pattern observed (Sorgente et al., 2011) is more affected by the superposition of the small scale vortex structures induced by the $\boldsymbol{U}_{3 D}$ field which finally eases the dispersion of the particles outside the SN and lowers the possibility that a particle be retained in the SN. Whereas this result can be expected for the internal zones $\mathrm{Zm8}, \mathrm{Zm11}, \mathrm{Zm12}, \mathrm{Zm} 13$ and $\mathrm{Zm} 14$, a similar outcome seems more surprising for zones $\mathrm{Zm} 9$ and $\mathrm{Zm} 10$. However, the analysis of some patterns of the particles initially released in $\mathrm{Zm9}$ (Figure 17) and $\mathrm{Zm} 10$ revealed that with the $\boldsymbol{U}_{3 D}$ field particles are more easily transported outside the Gulf of Tunis and the Gulf of Hammamet. Two selected 45-day particle-paths, with particles released on the same day and in the same positions within $\mathrm{Zm9}$, are shown in Figure 17: for the $\boldsymbol{U}_{U M S}+\boldsymbol{U}_{2 D}+\boldsymbol{U}_{3 D}$ and $\boldsymbol{U}_{U M S}+\boldsymbol{U}_{3 D}$ particles lie most of their time outside the SN and within the Gulf of Hammamet. Snapshots of the positions of selected particles initially released in $\mathrm{Zm8}, \mathrm{Zm} 9, \mathrm{Zm11}$ and $\mathrm{Zm12}$ are shown at 15,30 and 45 days in the supplementary material (Figure F3), where it is evident how particles are much more dispersed with the superposition of the $\boldsymbol{U}_{3 D}$ field.

The specific TS in 2004 and 2008 are also shown in Figure 11 in terms of connectivity matrices, where the TS are represented as circles whose diameter is proportional to the magnitude of the TS. Previous analysis are confirmed: the main differences arise in the case of the AN transport success when the $\boldsymbol{U}_{3 D}$ is not taken into account, given that $\boldsymbol{U}_{U M S}$ and $\boldsymbol{U}_{U M S}+\boldsymbol{U}_{2 D}$ show increasing TS, whereas less remarkable differences are observed in $\mathrm{SN}$ and $\mathrm{MN}$ transport success rates.

To investigate the variation of some of the parameters defining the fields $\boldsymbol{U}_{2 D}$ and $\boldsymbol{U}_{3 D}$ we performed several experiments in which some of the parameters were varied to analyse the sensitivity of the results.

The first experiment is related to the variation of parameter $I_{0}$ which in the previous sections was set at 
$I_{0}=20 \mathrm{~km}$, i.e. almost twice the maximum order of the first internal Rossby radius, which in the central Mediterranean is within the $5-12 \mathrm{~km}$ range (Grilli and Pinardi, 1998). We changed $I_{0}$ to be the $10-24 \mathrm{~km}$ range, so that $I_{0}$ was between twice the minimum and twice the maximum value of the Rossby radius admitted. We notice that varying parameter $I_{0}$ also leads to the variation of $\varepsilon=0.1 I_{0}, \omega=2 \pi A_{0} / I_{0}$ and $k=2 \pi / I_{0}$ so that the outcomes produced by varying $I_{0}$ can be also used to analyze the influence of these parameters on the overall dynamics. In this case we also present the results in terms of connectivity matrix of the TS. No remarkable variations were obtained, and we can only observe that decreasing value of $I_{0}$ led to increasing TS for the Zm1 (in the SN) and Zm8-Zm13 (in the AN), whereas the TS of the Zm6 decreased (in the $\mathrm{MN}$ ), these results being more evident in the year 2008.

The other free degree of freedom of the field $\boldsymbol{U}_{2 D}$ is $A_{0}$, which tunes the maximum velocity amplitude induced by $\boldsymbol{U}_{2 D}$. The outcomes in terms of TS produced are presented in Figure 13, with $A_{0}$ ranging from a minimum value of $0.001 \mathrm{~m} / \mathrm{s}$ to a maximum of $0.3 \mathrm{~m} / \mathrm{s}$. No clear trend resulted from varying this parameter, and the most evident result was obtained for the highest $A_{0}(0.3 \mathrm{~m} / \mathrm{s})$ when the TS in the $\mathrm{SN}$ region was lowered (with the exception of $\mathrm{Zm} 1$ ), probably due to a stronger dispersion induced by the more intense velocity field $\boldsymbol{U}_{2 D}$.

We conclude this appendix by showing the experiments related to the sensitivity analysis of parameters $I_{1}$ and $I_{2}$ in $\boldsymbol{U}_{3 D}$. These parameters set the wavelengths of the $3 \mathrm{D}$ vortex structures induced by $\boldsymbol{U}_{3 D}$, and similarly to $I_{0}$ in $\boldsymbol{U}_{2 D}$ they also define the other parameters of $\boldsymbol{U}_{3 D}$, with the exception of velocity intensities $A_{1}$ and $A_{2}$. Results in Figure 14 are shown for moderate-low values to high values of $I_{1}$ and $I_{2}$. In this case, similarly to the results for the sensitivity of $I_{0}$, no remarkable variations in the TS were observed.

The main outcome of these experiments is that the results in terms of TS are predominantly affected by the inclusion of the $\boldsymbol{U}_{3 D}$ and $\boldsymbol{U}_{2 D}$, and only secondarily by the specific variation of one of the parameters of the two fields, at least for the ranges chosen in our sensitivity experiments. This implies some robustness in the quantitative results presented in Section 3 in terms of TS and connectivity rates between the Sicilian and African coasts. It also shows that the main role is played by $\boldsymbol{U}_{3 D}$ with its induced vertical mixing and small scale vortical structures. Palatella et al. 2014 performed analyses on the reliability of the kinematic Lagrangian model used in this work: experiments were carried out to test the robustness of the model when determining the Lagrangian Transport Index (LTI) of anchovy larvae in the Sicily Channel. Similarly to our results, the authors found that the predicted LTI values were marginally influenced by the variation of the parameters of the model, even in the case of large differences. Furthermore, as suggested in subsequent studies by Lacorata et al. 2015, the only factor that matters is that the eddy fields used to replace unresolved velocity components of the $\boldsymbol{U}_{\text {UMS }}$ model have length and time scales compatible with the physics of the system, without necessarily introducing a more refined velocity fields characterized by other wavelengths. From the numerical experiments reported in this work, and in the cited in Palatella et al. 2014 and Lacorata et al. 2015 we assume that the Lagrangian model proposed is able to capture, at least from a statistical point of view, some of the features characterizing the dispersal of larvae in the central area of Mediterranean sea.

\section{Acknowledgements}

This paper was written in the framework of the Italian flag project RITMARE, funded by Ministry of Education, University and Research. Authors warmly thank all the CNR-IAMC Colleagues of Mazara del Vallo (Sicily) involved in the GRUND and MEDITS projects, supported by the Ministry of Agricultural, Food and Forestry Policies and the European Commission, since 2002 within the European DCR \& DCF. We thank F. 
Bignami and E.B. Morello for useful comments, and the two anonymous referees for their valuable suggestions and criticisms which greatly improved the manuscript.

Finally, authors thank people participating to the FAO regional Project MedSudMed who enabled the joint analyses of Italian, Maltese and Tunisian trawl survey data towards identifying the spawning areas of red mullet in the Strait of Sicily.

\section{References}

1 Agostini, V.N., Bakun, A. (2002). Ocean Triads in the Mediterranean Sea: physical mechanisms potentially structuring reproductive habitat suitability (example application to European anchovy, Engraulis encrasicolus). Fish. Oceanogr. 11, 128-142.

2 Béranger K., Astraldi M., Crépon M., Mortier L., Gasparini G.P., and Gervaso, L. (2004). The dynamics of the Sicily Strait: a comprehensive study from observations and models. Deep-Sea Res. Pt. II., 411440 .

3 Boffetta G.A., Celani A., Crisanti A., Vulpiani A. (1999). Pair dispersion in synthetic fully developed turbulence, Phys. Rev. E, 60:6734-6741.

4 Bonanno A., Zgozi S., Cuttitta A., El Turki A., Di Nieri A., Ghmati H., Basilone G., Aronica S., Hamza M., Barra M., Genovese S., Falco F., Knittweis L., Mifsud R., Patti B., Bahri T., Giacalone G., Fontana I., Tranchida G., Mazzola S. (2013). Influence of environmental variability on anchovy early life stages (Engraulis encrasicolus) in two different areas of the Central Mediterranean Sea. Hydrobiologia 701(1): 273-287.

5 Bradbury I.R., Snelgrove P.V.R. (2001). Contrasting larval transport in demersal fish and benthic invertebrates: the roles of behavior and advective processes in determining spatial pattern. Canadian Journal of Fisheries and Aquatic Sciences, 58(4): 811-823.

6 Calò, A., Félix-Hackradt, F.C., Garcia, J., Hackradt, C.W., Rocklin, D., Treviño Otón, J., García Charton, J.A. (2013). A review of methods to assess connectivity and dispersal between fish populations in the Mediterranean Sea. Advances in Oceanography and Limnology 4(2):150-155.

7 Catalán I. A., Macías D., Jordi S., Ospina-Alvarez A. (2013). Stay off the motorway: resolving the prerecruitment life history dynamics of the European anchovy in the SW Mediterranean through a spatially-explicit individual-based model (SEIBM). Progress in oceanography 111: 140-153.

8 Chelton D. B., de Szoeke R. A., Schlax M. G., El Naggar K. and Siwertz N. (1998). Geographical variability of the first baroclinic Rossby radius of deformation, J. Phys. Oceanogr., 28:433-459.

9 Colloca F., Spedicato M. T., Massutí E., Garofalo G., Tserpes G., Sartor P., Mannini A., Gas A. L., Mastrantonio G., Reale B., Musumeci C., Rossetti I., Sartini M., Sbrana M., Grati F., Scarcella G., Iglesias M., Tugores M.P., Ordines F., Gil de Sola L., Lembo G., Bitteto I., Facchini M.T., Martiradonna A., Zupa W., Carlucci R., Follesa M.C., Carbonara P., Mastradonio A., Fiorentino F., Gristina M., Knittweis L., Mifsud R., Pace M.L., Piccinetti C., Manfredi C., Fabi G., Polidori P., Bolognini L., De Marco R., 
Domenichetti F., Gramolini R., Valavanis V., Lefkaditou E., Kapiris K., Anastasopoulou A. and Nikolioudakis N. (2013). Mapping of nursery and spawning grounds of demersal fish. Mediterranean Sensitive Habitats (MEDISEH) Final Report, DG MARE MAREA, Specific Contract No 2 SI2.600741.

Cowen R.K, Sponaugle S. (2009). Larval Dispersal and Marine Population Connectivity. Ann. Rev. Mar. Sci., 1:443-66.

11 Di Franco A., Gillanders B.M., De Benedetto G., Pennetta A., De Leo G.A., Guidetti P. (2012). Dispersal Patterns of Coastal Fish: Implications for Designing Networks of Marine Protected Areas. PLOS ONE 7(2):e31681

12 Falcini F., Palatella L. Cuttitta A., Buongiorno Nardelli B., Lacorata G., Lanotte A.S., Patti B., Santoleri R. (2015). The Role of Hydrodynamic Processes on Anchovy Eggs and Larvae Distribution in the Sicily Channel (Mediterranean Sea): A case Study for the 2004 Data Set. Plose One 10(4): e0123213.

13 Félix-Hackradt F.C., Hackradt C.W., Treviño-Otón J., SegoviaViadero M., Pérez-Ruzafa A. (2013). Discordant patterns of genetic connectivity between two sympatric species, Mullus barbatus (Linnaeus, 1758) and Mullus surmuletus (Linnaeus, 1758) in South-western Mediterranean Sea. Marine Environmental Research, 92:23-34.

14 Fiorentini L., Caddy J.F., De Leiva J.I. (1997). Long- and short-term trends of Mediterranean fishery resources. General Fisheries Council for the Mediterranean (FAO, Rome) Studies and Reviews 69:72pp.

15 Fiorentino, F., Ben Merie, S., Bahri T., Camilleri M., Dimech M., Ezzeddine-Naja S., Mass, F., Jarboui O., Zgoz S. (2008). Synthesis of information on some target species in the MedSudMed Project area (central Mediterranean). GCP/RER/010/ITA/MSM-TD-15. MedSudMed Technical Documents, 15: 67 pp.

Fiorentino F., Massutì E., Tinti F., Somarakis S., Garofalo G., Russo T., Facchini M.T., Carbonara P., Kapiris K., Tugores P., Cannas R., Tsigenopoulos C., Patti B., Colloca F., Sbrana M., Mifsud R., Valavanis V., Spedicato M.T. (2015). Stock units: Identification of distinct biological units (stock units) for different fish and shellfish species and among different GFCM-GSA (STOCKMED). Final Report. DG MARE MAREA Project Specific Contract No 7 SI2.642234.

17 Galarza J.A., Turner G.F., Macpherson E., Rico C. (2009). Patterns of genetic differentiation between two co-occurring demersal species: The red mullet (Mullus barbatus) and the striped red mullet (Mullus surmuletus). Canadian Journal of Fisheries and Aquatic Sciences, 66(9):1478-1490.

18 Garofalo G., Bel Hassen M., Jarboui O., Zgozi S., Gristina M., Fiorentino F., Ragonese S., Camilleri M. (2008). Preliminary results on spatial distribution of abundance indices, nursery and spawning areas of Merluccius merluccius and Mullus barbatus in the central Mediterranean.GCP/RER/010/ITA/MSM19 (MedSudMed Technical Documents n¹9): $24 \mathrm{pp}$.

19 Garofalo G., Fiorentino F., Bono G., Gancitano S., Norrito G. (2004). Localisation of spawning and nursery areas of Red Mullet (Mullus barbatus, Linnaeus) on the Italian side of the Strait of Sicily 
(central Mediterranean). Nishida T., P.J. Kaiola, C.E. Hollingworth (eds.) GIS/Spatial Analyses in Fishery and Aquatic Sciences 2.Fishery-Aquatic GIS Research Group, Saitama, Japan. pp101-110.

Garofalo G., Fortibuoni T., Gristina M., Sinopoli M. and Fiorentino F. (2011). Persistence and cooccurrence of demersal nurseries in the Strait of Sicily (Central Mediterranean): implications for fishery management. Journal of Sea Research, 66:29-38.

21 Getis A. and Ord. J.K. (1992). The analysis of spatial association by use of distance statistics. Geographical Analysis, 24:189-206.

Gill A. E.(1982). Atmosphere-Ocean Dynamics, Academic Press, pp662.

Goethel D.R., Quinn II T.J., Cadrin S.X. (2011). Incorporating spatial structure in stock assessment: movement modelling in marine fish population dynamics. Rev. Fish. Sci.19 (2): 119-136.

Grilli F. and Pinardi N. (1998). The computation of Rossby radii of deformation for the Mediterranean Sea , MTP News, 6(4).

Heath M.R., Kunzlik P.A., Gallego A., Holmes S.J., Wright P.J. (2008). A model of meta-population dynamics for North Sea and west of Scotland codethe dynamic consequences of natal fidelity. Fish. Res. 93: 92-116.

Hilborn R., Quinn T.P., Schindler D.E., Rogers D.E. (2003). Biocomplexity and fisheries sustainability. Proc. Natl. Acad. Sci. 100 (11): 6564-6568.

27 Huret, M., Runge, J.A., Chen, C., Cowles, G., Xu, Q. and Pringle, J.M. (2007) Dispersal modeling of fish early life stages: sensitivity with application to Atlantic cod in the western Gulf of Maine. Mar. Ecol. Prog. Ser. 347:261-274

28 Kerr L.A., Cadrin S.X., Secor D.H. (2010)a. Simulation modelling as a tool for examining the consequences of spatial structure and connectivity on local and regional population dynamics. ICES J. Mar. Sci. 67:1631-1639.

29 Kerr L.A., Cadrin S.X., Secor D.H. (2010)b. The role of spatial dynamics in the stability, resilience, and productivity of an estuarine fish population. Ecol. Appl. 20 (2): 497-507.

Kerr L.A., Goethel D.R. (2014), Simulation Modeling as a Tool for Synthesis of Stock Identification Information. In: Stock Identification Methods (Second Edition), edited by Steven X. Cadrin, Lisa A. Kerr, Stefano Mariani, Academic Press, San Diego,pp 501-533.

31 Lambert, J. D. and Lambert, D. (1991).Numerical Methods for Ordinary Differential Systems: The Initial Value Problem. New York: Wiley

32 Lacora G., Palatella L., Santoleri R. (2014), Lagrangian predictability characteristics of an Ocean Model, J. Geophys. Res. Oceans,119: 8029-8038 

large-eddy simulations, J. Atmos. Sci., 65:2389-2401.

34 Levi D., Andreoli M.G., Rizzo P. (1992). Growth curves from representative samples of fish populations as possible hints for the identification of unit stocks. The case study of Red Mullet from the Sicilian Channel. Colombo G., Ferrari I., Ceccherelli V.U. \& Rossi R. (eds.), Marine Eutrophication and Population Dynamics. Olsen \& Olsen Publ. and Printers, pp 299-306.

Levi D., Andreoli G., Rizzo P. (1995). Independence of water masses and independence of stocks. Rapp. Comm. Int. Mer Medit. 34:248pp.

Levi D., Andreoli M.G., Bonanno A., Fiorentino F., Garofalo G., Mazzola S., Norrito G., Patti B., Pernice G., Ragonese S., Giusto G.B., Rizzo P. (2003). Embedding sea-surface temperature anomalies in the stock-recruitment relationship of Red Mullet (Mullus barbatus L. 1758) in the Strait of Sicily. Sci. Mar. 67(1):259-268

Lleonart J., Maynou F. (2003). Fish stock assessments in the Mediterranean:state of the art. Sci. Mar. 67 (1):37-49.

Maggio T., Lo Brutto S., Garoia F., Tinti F., Arculeo M. (2009). Microsatellite analysis of red mullet Mullus barbatus (Perciformes, Mullidae) reveals the isolation of the Adriatic Basin in the Mediterranean Sea. ICES J. Mar. Sci, 66:1883-1891

McCormick M.I. (1999). Delayed metamorphosis of a tropical reef fish (Acanthurus triostegus): a field experiment. Mar. Ecol. Prog. Ser. 176: 23-38.

40 Montalenti, G. (1933). Mullidae: In: Uova, larve e stadi giovanili di Teleostei. Fauna e Flora del Golfo di Napoli, 38.

41 Murenu M., Muntoni M., Rocklin D., Frongia C., Calò A., García-Charton J.A., Giacalone V.M., Carta G., Vega-Fernandez T., D'Anna G. (2014). Settlement synchronization in the red mullet (Mullus barbatus) as inferred from otolith sclerochronology. $5^{\text {th }}$ International Otoliths Symposium, October 20-24, 2014 Casal de Peguera, Peguera (Calvià), Mallorca, Spain. Book of abstract: 75-76

42 Nicolle A., Garreau P., Liorzou B. (2009). Modelling for anchovy recruitment studies in the Gulf of Lions (Western Mediterranean Sea). Ocean dynamics 59(6): 953-968.

43 Nieto K., McClatchie S., Weber E.D., Lennert- Cody C.E. (2014). Effect of mesoscale eddies and streamers on sardine spawning habitat and recruitment success off Southern and Central California. Journal of Geophysical Researc: Oceans. 119: 6330-6339. 
Olivar M. P., and Sabatés A. (1997) Vertical distribution of fish larvae in the north-west Mediterranean Sea in spring. Marine Biology, 129(2):289-300.

Ord J.K. and Getis A. (1995). Local spatial autocorrelation statistics: distributional issues and an application, Geographical Analysis, 27:286-306.

47 Ospina-Alvarez A., Parada C., Palomera I. (2012). Vertical migration effects on the dispersion and recruitment of European anchovy larvae: From spawning to nursery areas. Ecological Modelling 231:65-79.

Palatella L., Bignami F., Falcini F., Lacorata G., Lanotte A. S., and Santoleri R. (2014). Lagrangian simulations and interannual variability of anchovy egg and larva dispersal in the Sicily Channel, Journal of Geophysical Research: Oceans, 119:1306-1323.

Pinardi N. and Masetti E. (2000). Variability of the large scale circulation of the Mediterranean Sea froma observations and modeling: a review. Palaeogeography, Palaeoclimatology, Palaeoecology 158:153-173.

50 Pinardi N., Arneri E., Crise A., Ravaioli M., Zavatarelli M. (2006). The physical, sedimentary and ecological structure and variability of shelf areas in the Mediterranean Sea. In: A.R. Robinson and K. Brink (eds.) The Sea, vol. 14, Harvard University Press, Cambridge, Mass., USA, pp1243-1330.

51 Pineda J., Har J.A., Spounaugle S. (2007). Larval Transport and Dispersal in the Coastal Ocean and Consequences for Population Connectivity. Oceanography 20(3):22-39.

52 Reiss H., Hoarau G., Dickey-Collas M., Wolff W. (2009). Genetic population structure of marine fish: mismatch between biological and fisheries management units. Fish Fish. 10: 361-395.

53 Roughgarden J., Gaines S., Possingham H. (1988). Recruitment dynamics in complex life cycles. Science 241: 1460-1466.

54 Sabatés A., Olivar M. P., Salat, J., Palomera I., Alemany F. (2007). Physical and biological processes controlling the distribution of fish larvae in the NW Mediterranean. Progress in Oceanography, 74(2), 355-376.

Sabatés A. and Palomera I. (1987). Repartition des larves du rouget de vase (Mullus barbatus, L., 1758) le long de la cote catalane (Méditerranée occidentale). Vie et Milieu, 37 (3/4) : $207-214$.

56 Saenko O. A. (2006). Influence of global warming on baroclinic Rossby radius in the ocean: a model intercomparison, J. Climate, 19:1354-1360.

57 Santora J.A., Vetit R.R. (2013). Spatio-temporal persistence of top predator hotspots near the Antarctic Peninsula, Mar. Ecol. Progr. Series, 487: 287-304. 
59 Schmitten R.A. (1999). Essential Fish Habitat: opportunities and challenges for the next Millennium. In: Benaka L.R. (Ed.), Fish Habitat: Essential Fish Habitat and rehabilitation. American Fisheries Society, Symposium 22, Bethesda, Maryland.,pp 3-10.

Schunter, C., Carreras-Carbonell, J., Macpherson, E., Tintore, J., Vidal-Vijande, E., Pascual, A., Guidetti, P., Pascual, M. (2011). Matching genetics with oceanography: directional gene flow in a Mediterranean fish species. Molecular Ecology 20: 5167-5181.

61 Slatkin M. (1993). Isolation by distance in equilibrium and nonequilibrium populations. Evolution 47:264-279.

62 Somarakis S., Nikolioudakis N., (2007). Oceanographic habitat, growth and mortality of larval anchovy (Engraulis encrasicolus) in the northern Aegean Sea (eastern Mediterranean). Marine Biology, 152(5), 1143-1158.

63 Sorgente R. Drago A., Ribotti A., (2003). Seasonal variability in the Central Mediterranean Sea circulation, Ann. Geophys., 21:299-322.

64 Sorgente R., Olita A., Oddo P., Fazioli L., and Ribotti A. (2011), Numerical simulation and decomposition of kinetic energy in the Central Mediterranean: Insight on mesoscale circulation and energy conservation, Ocean Sci., 7:503-519.

65 Tonani M., Pinardi N., Pistoia J., Dobricic S., Pensieri S., de Alfonso M., Nittis K. (2009). Mediterranean forecasting system: Forecast and analysis assessment through skill scores. Ocean Sci., 5, 649-660.

66 Tserpes G., Fiorentino F., Levi D., Cau A., Murenu,M., Zamboni A., and Papaconstantinou C. (2002). Distribution of Mullus barbatus and M. surmuletus (Osteichthyes: Perciformes) in the Mediterranean continental shelf: implications for management. Scientia Marina, 66: 39-54.

67 Voliani, A. (1999). Mullus barbatus. In Synthesis of the Knowledge on Bottom Fishery Resources in Central Mediterranean (Italy and Corsica). Ed. by G. Relini, J. Bertrand, and A. Zamboni. Biologia Marina Mediterranea, Genova, pp. 276-289.

68 Zarrad R., Alemany F, Rodriguez J-M, Jarboui O., Lopez-Jurado J-L, Balbin R.,(2013). Influence of summer conditions on the larval fish assemblage in the eastern coast of Tunisia (Ionian Sea, Southern Mediterranean). Journal of Sea Research 76: 114-125. 


\begin{tabular}{|c|c|c|c|c|c|c|c|c|}
\hline \multirow[t]{2}{*}{ Zone } & \multicolumn{2}{|l|}{ SN } & \multicolumn{2}{|l|}{$\mathrm{MN}$} & \multicolumn{2}{|l|}{ AN } & \multirow[b]{2}{*}{$\bar{r}_{Z}^{\text {loss }}$} & \multirow[b]{2}{*}{ s.d } \\
\hline & $\bar{r}_{Z}^{S N}$ & s.d & $\bar{r}_{Z}^{M N}$ & s.d & $\bar{r}_{Z}^{A N}$ & s.d & & \\
\hline & 0,2583 & 0,0515 & 0,0016 & 0,0016 & 0,0002 & 0,0003 & 0,7400 & 0,0292 \\
\hline $7 m ?$ & 0,1371 & 0,1545 & 0,0033 & 0,0041 & 0,0000 & 0,0000 & 0,8595 & 0,0880 \\
\hline & 0,0558 & 0,0608 & 0,0005 & 0,0011 & 0,0001 & 0,0002 & 0,9436 & 0,0348 \\
\hline & 0,0001 & 0,0002 & 0,0040 & 0,0072 & 0,0002 & 0,0008 & 0,9957 & 0,0039 \\
\hline & 0,0069 & 0,0033 & 0,0013 & 0,0082 & 0,0264 & 0,0253 & 0,9654 & 0,0116 \\
\hline & 0,0005 & 0,0000 & 0,0575 & 0,0322 & 0,0000 & 0,0001 & 0,9419 & 0,0185 \\
\hline Zm7 & 0,0003 & 0,0005 & 0,0475 & 0,0100 & 0,0002 & 0,0007 & 0,9519 & 0,0054 \\
\hline $7 \mathrm{me}$ & 0,0002 & 0,0005 & 0,0093 & 0,1389 & 0,5767 & 0,0830 & 0,4138 & 0,0696 \\
\hline & 0,0034 & 0,0028 & 0,0054 & 0,0497 & 0,1191 & 0,0644 & 0,8721 & 0,0322 \\
\hline 7. & 0,0033 & 0,0022 & 0,0143 & 0,0207 & 0,0746 & 0,0361 & 0,9077 & 0,0170 \\
\hline & 0,0000 & 0,0000 & 0,0310 & 0,0373 & 0,1519 & 0,0686 & 0,8171 & 0,0343 \\
\hline & 0,0000 & 0,0000 & 0,0036 & 0,1180 & 0,4647 & 0,0558 & 0,5316 & 0,0590 \\
\hline $7 \mathrm{~m}^{12}$ & 0,0000 & 0,0000 & 0,0008 & 0,0091 & 0,0685 & 0,0369 & 0,9307 & 0,0192 \\
\hline Zm14 & 0,0008 & 0,0021 & 0,0036 & 0,0073 & 0,0187 & 0,0123 & 0,9768 & 0,0051 \\
\hline
\end{tabular}

Table 1: Mean and standard deviation of larval the transport success for eggs released in zones $\mathrm{Zm1-Zm7} \mathrm{(spawning} \mathrm{areas} \mathrm{on}$ Sicilian-Maltese shelf) and Zm8-Zm14 (spawning areas on African shelf) reaching the SN, MN, AN nurseries as settlers. The mean larval fraction lost (larvae not reaching any nursery in the study area) is also shown. 


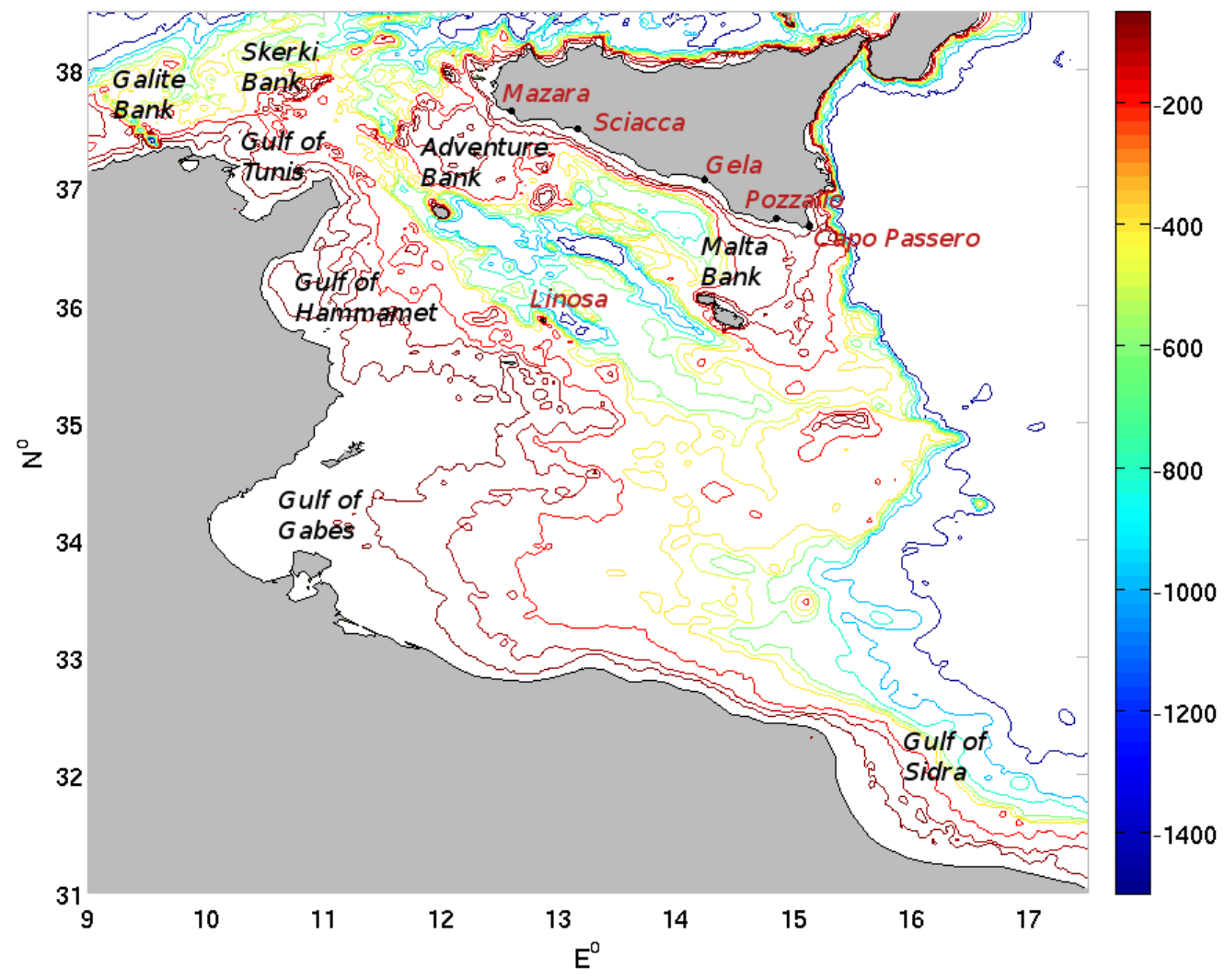

Figure 1: Bathymetric map of the Strait of Sicily and adjacent areas. 


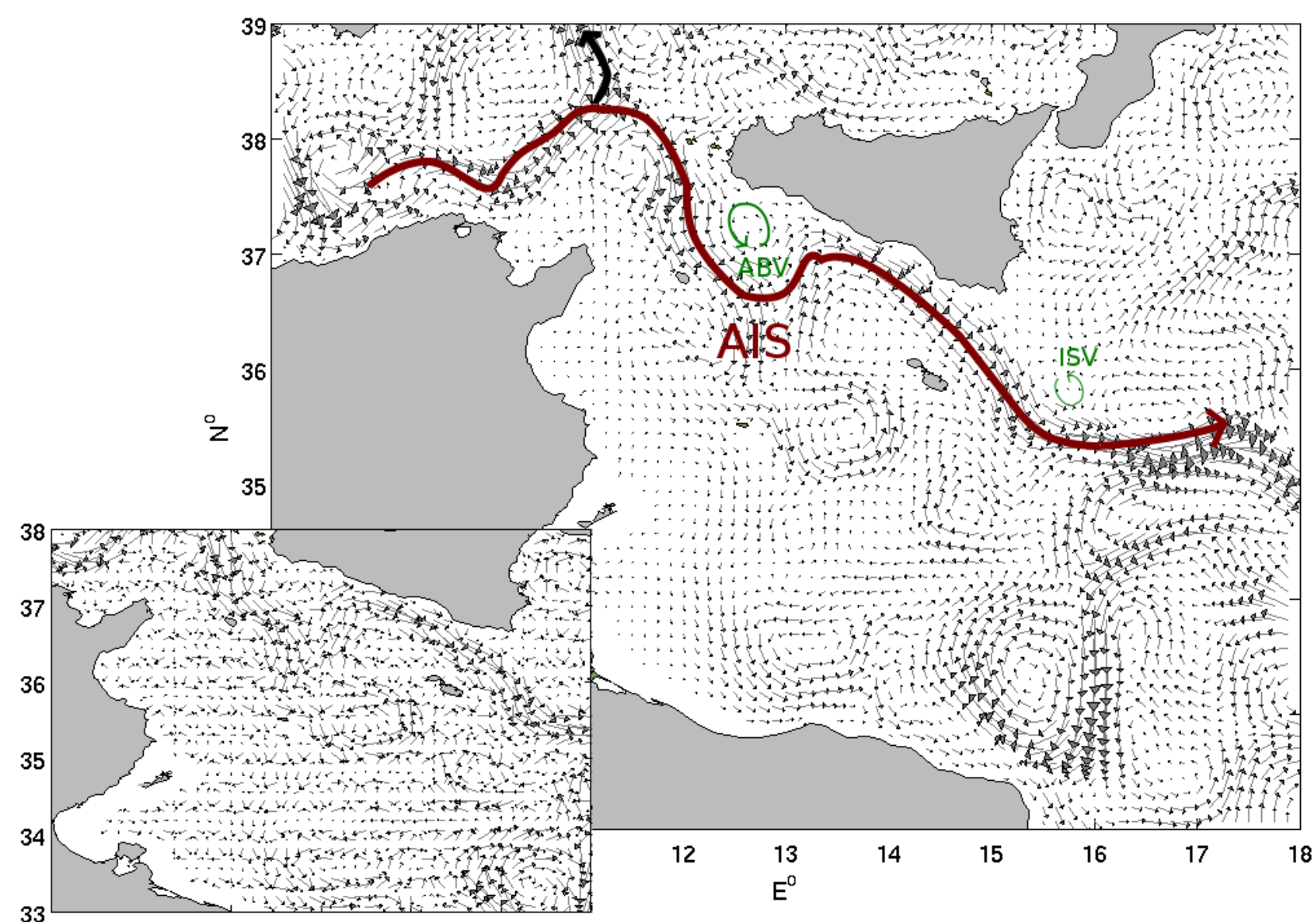

$\begin{array}{lllllll}10 & 11 & 12 & 13 & 14 & 15 & 16\end{array}$ path is indicated by the brown arrow. The locations of the Adventure Bank Vortex (ABV) and the lonian Shelf-break Vortex (ISV) are also shown (green arrows), though the vortices are weak in this case. In the inset the $2 \mathrm{D}$ field $\boldsymbol{U}_{2 D}$ is superimposed to $\boldsymbol{U}_{\mathrm{MFs}}$, where $t=12 \mathrm{hr}$ in $\boldsymbol{U}_{2 D}$. 


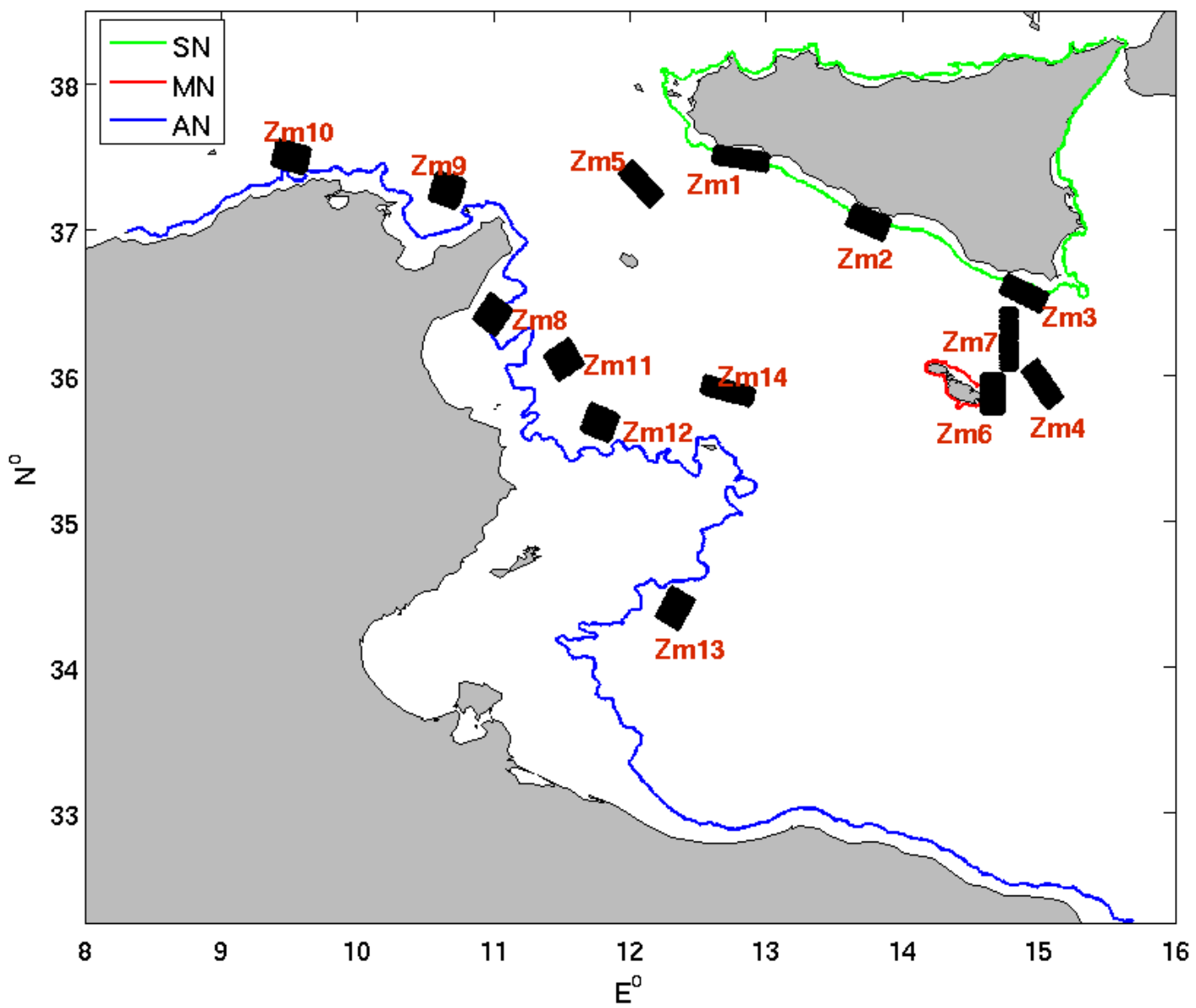

Figure 3: The simulation scenario to explore the connectivity between Essential Fish Habitats of red mullet in the Strait of Sicily showing the spawning areas Zm1-Zm14 in which the eggs are released. The continuous lines represent the $60 \mathrm{~m}$ bathymetric contours, deemed the ideal boundaries of the Red Mullet potential nurseries : AN - African Nursery (blue), MN - Maltese Nursery (red), SN - Sicilian Nursery (green). 


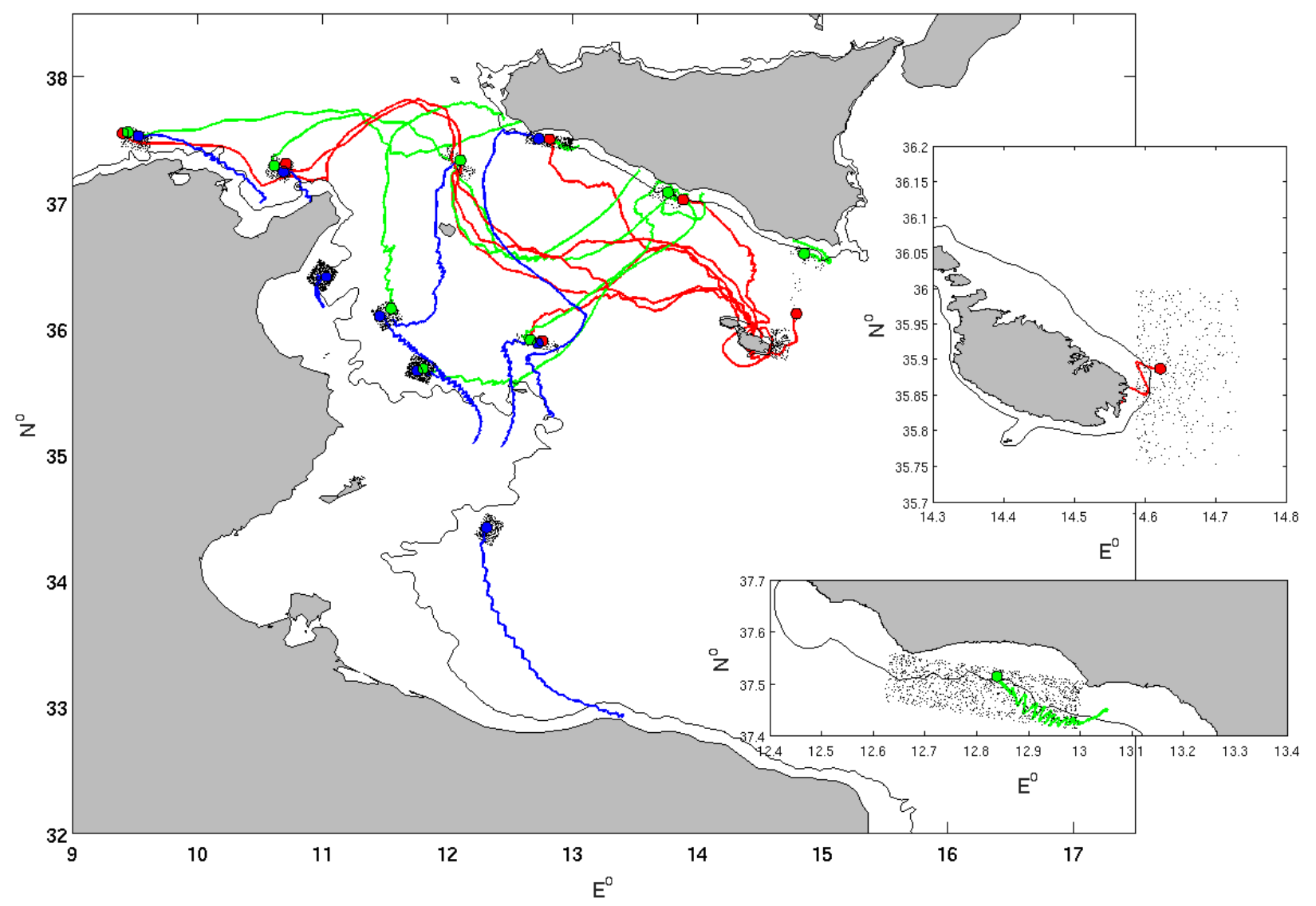

Figure 4: Initial position of the eggs (small black dots) released in Zm1-Zm14 reaching respectively the nurseries SN (green), MN (red) and AN (blue) in 2004 and average trajectories of larvae arriving into the nurseries. Insets: initial position of the eggs (colored dots) released in $\mathrm{Zm1}$ and $\mathrm{Zm3}$ and average trajectories of larvae arriving into the nurseries of southwestern Sicily (top right), southeastern Sicily (bottom right). The starting point of the average trajectories is marked with a colored point. 


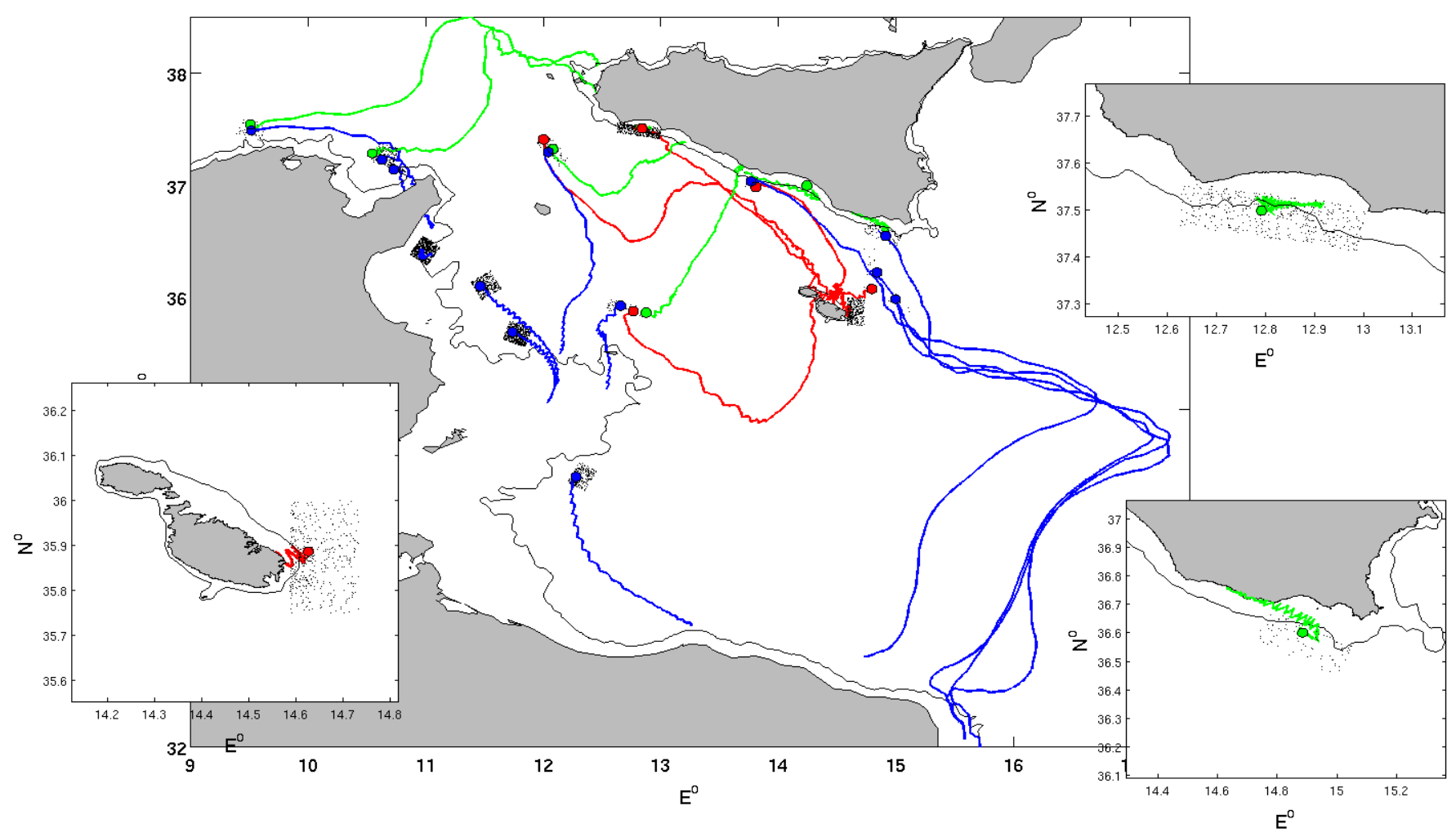

Figure 5: Initial position of the eggs (small black dots) released in Zm1-Zm14 reaching respectively the nurseries SN (green), MN (red) and AN (blue) in 2008 and average trajectories of larvae arriving into the nurseries. Insets: initial position of the eggs released in $\mathrm{Zm1}, \mathrm{Zm3}$ and $\mathrm{Zm} 6$ and average trajectories of larvae arriving into the nurseries of southwestern Sicily (top right), southeastern Sicily (bottom right) and eastern Malta (bottom left). The starting point of the average trajectories is marked with a colored point. 


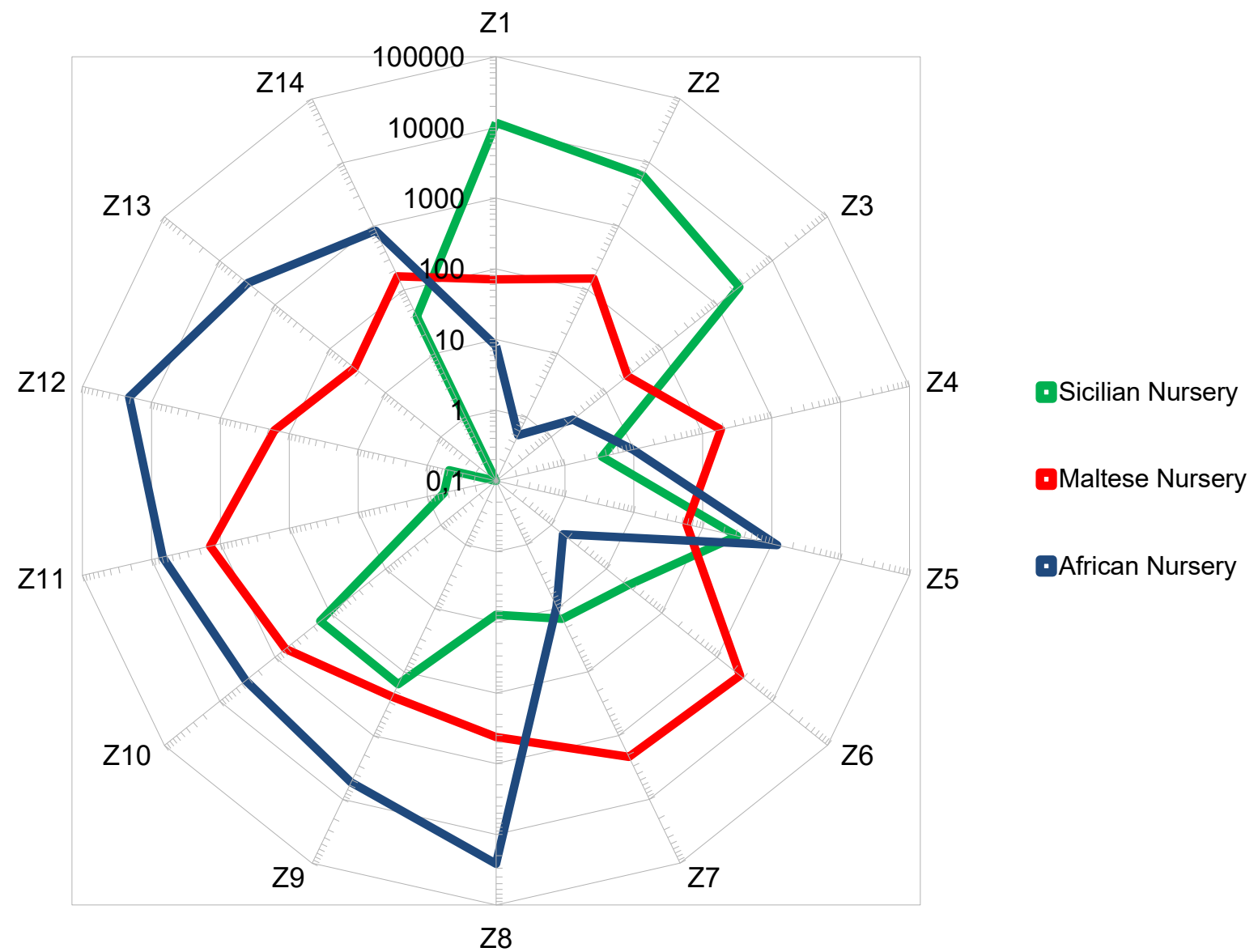

Figure 6: Radar chart displaying the relative contribution of each spawning area Zm1-Zm14 in terms of total number (in log-scale) of larvae arrived into the potential nurseries SN, MN and AN for the period 1999 to 2012. The total number of eggs released is 634872 . Only larvae having transport success higher than 0.75 are considered. 


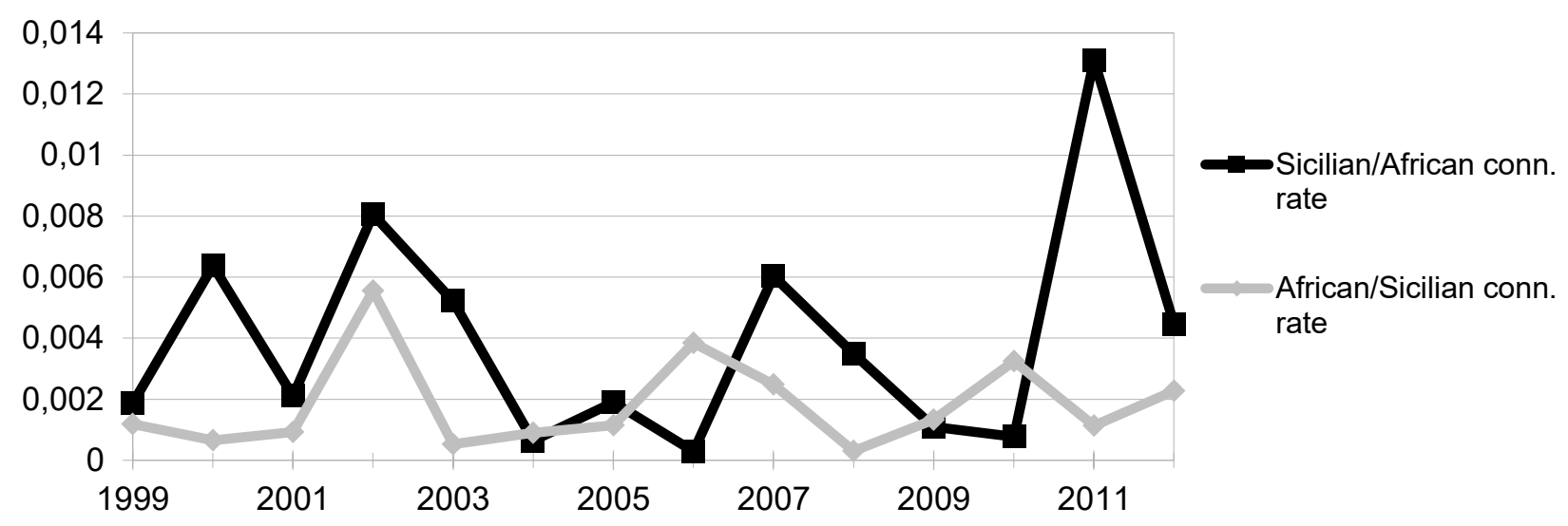

Figure 7: The overall annual larval transport success $s c_{j}^{A N}$ of eggs released in the Sicilian-Maltese spawning areas $\mathrm{Zm1-Zm7}$ arriving into the African nursery AN (black line) and the overall annual larval transport success $c_{j}^{S N}+c_{j}^{M N}$ of eggs released in the African spawning areas $\mathrm{Zm8-Zm14}$ arriving into the Sicilian-Maltese nurseries SN and MN (gray line). 


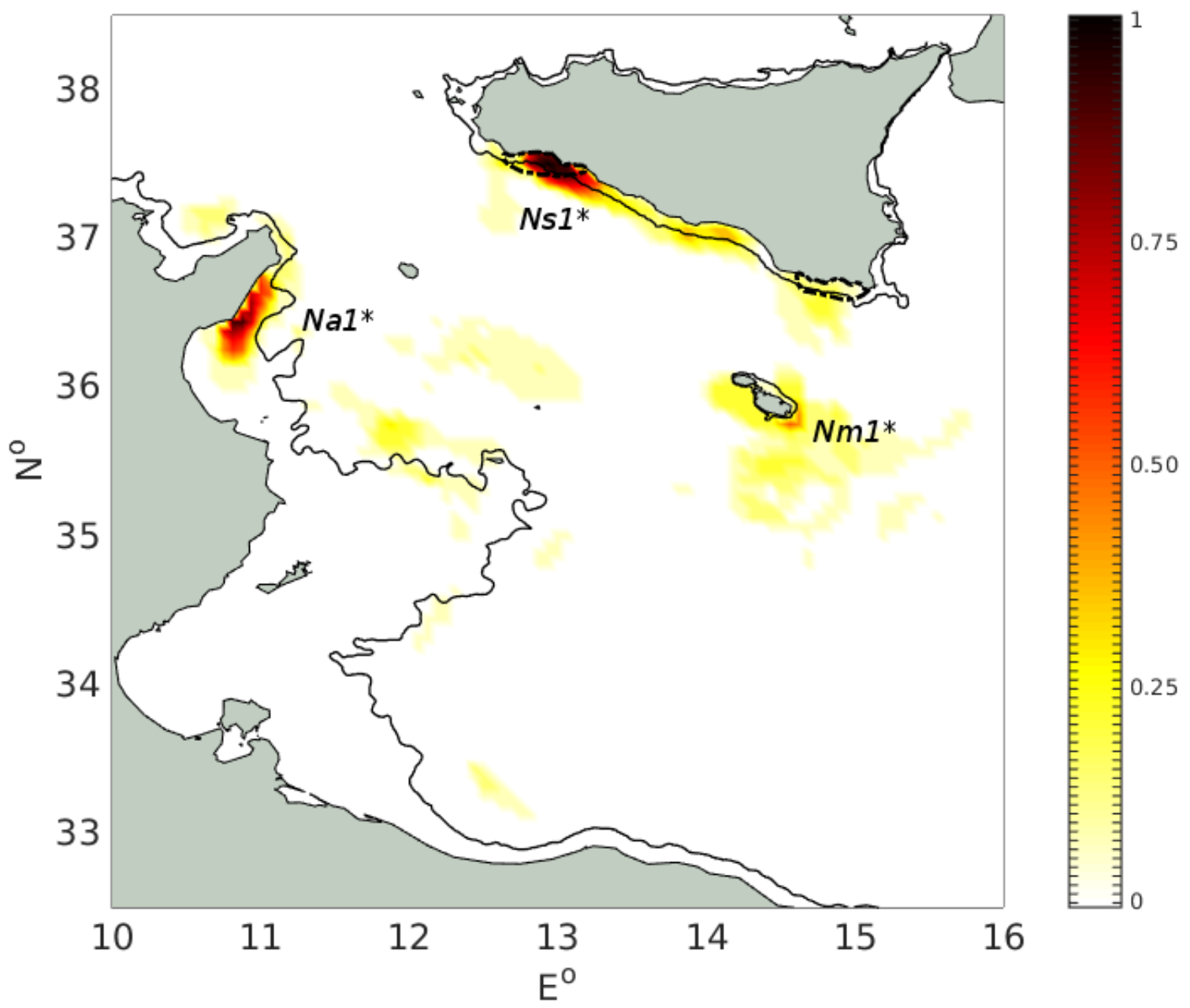

Figure 8: Persistence index $\left(\mathrm{PI}^{*}\right)$ of the settler hotspot areas in the period 1999-2012 computed with the gi*-hotspot analysis. The $60 \mathrm{~m}$ bathymetric contour (black line) is shown. Three main persistent settler hotspots (high $\mathrm{PI}^{*}$ ) are visible: $\mathrm{Ns1}{ }^{*}, \mathrm{Nm1}$, $\mathrm{Na1}$. No relevant $\mathrm{PI}{ }^{*}$ value occurs outside the boundaries of the figure. The black dashed line are the relevant nurseries identified in Garofalo et al 2011. 


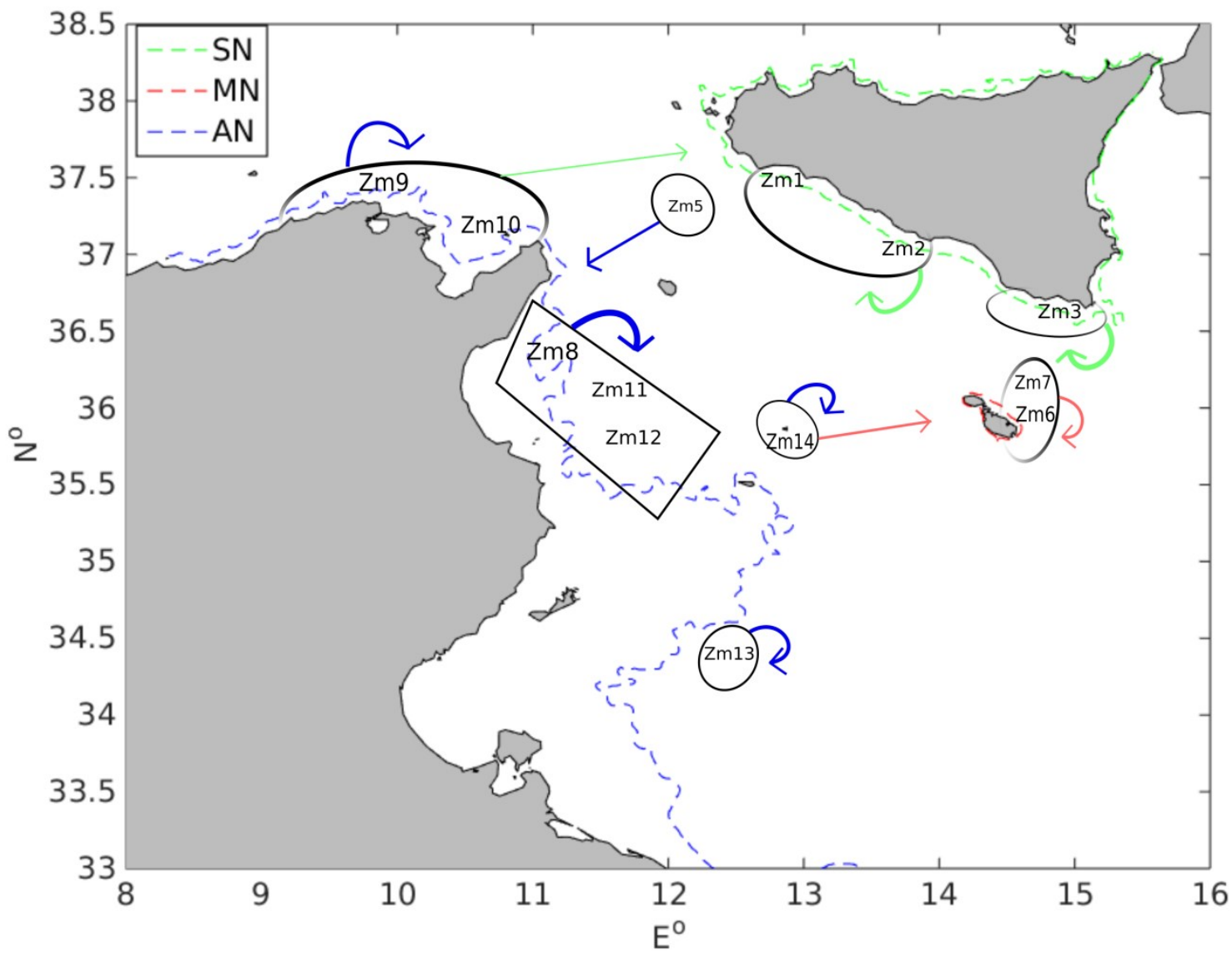

Figure 9: Schematic representation of the simulated larval drift of red mullet in the Sicilian and African shelves of the SoS based on the initial condition shown in Figure 3. Only the spawning areas having transport success greater than $\mathbf{0 . 0 0 5}$ (Table 1) are shown. Close spawning areas showing similar dispersal patterns are aggregated in larger reproductive spatial units . Arrows schematise drift from spawning to nursery areas, and curved arrows illustrate possible retention regions (self-recruitment processes). The width of the arrows increases with the larval transport success into the various nurseries (see Table 1). 


\section{SN rate}

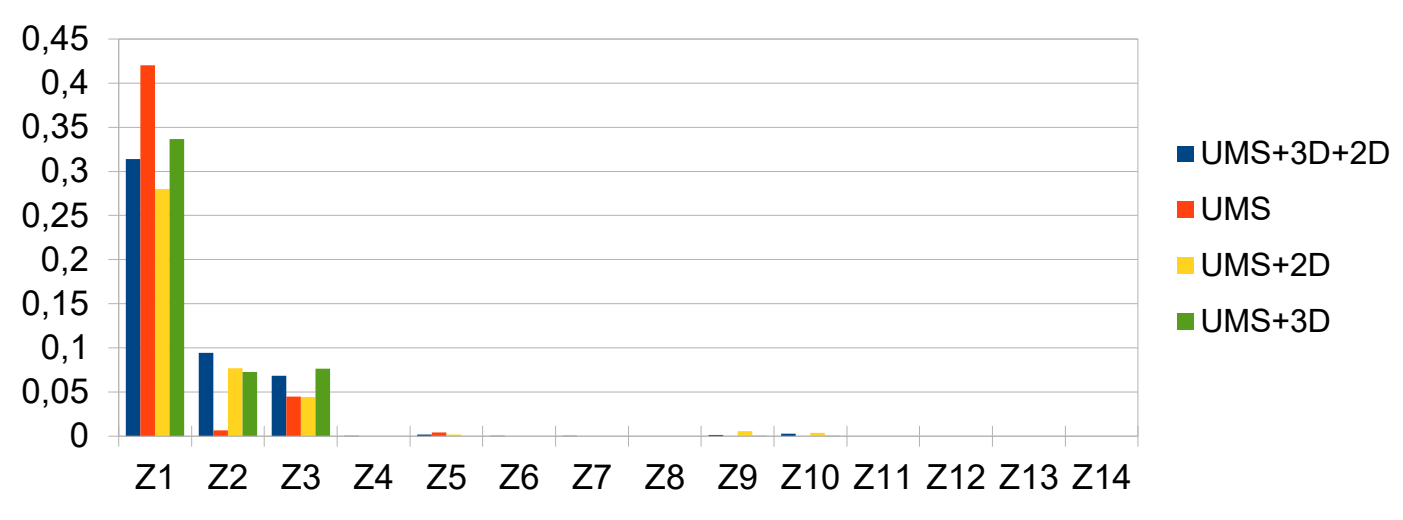

MN rate

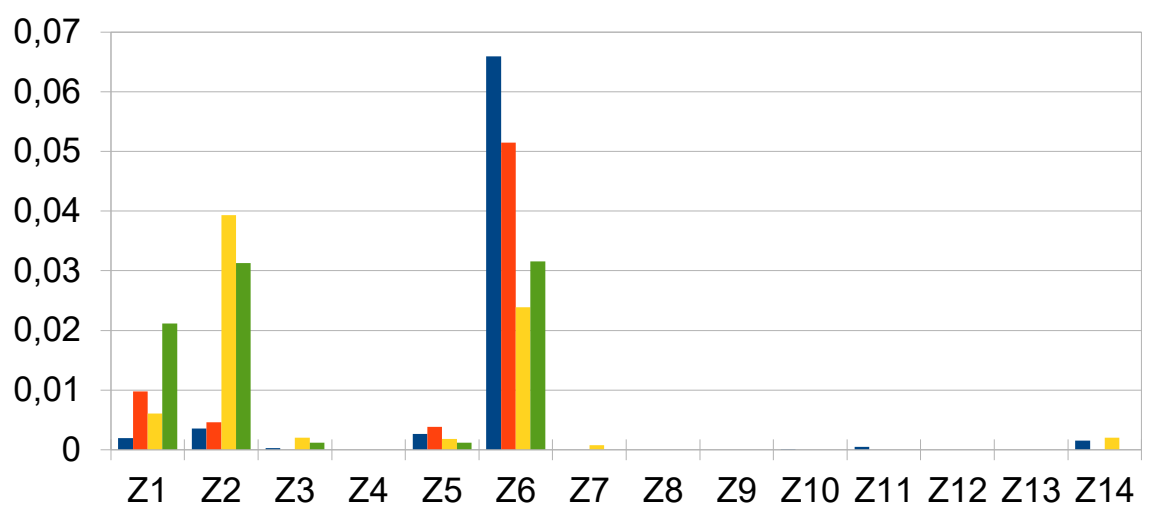

- UMS+3D+2D

- UMS

- UMS+2D

- UMS+3D

AN rate

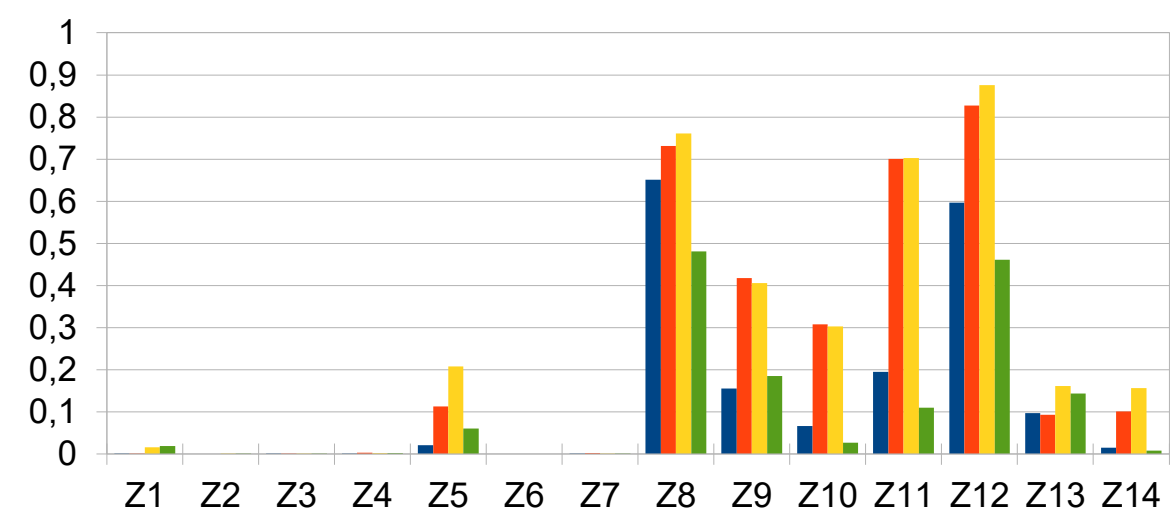

- UMS+3D+2D

- UMS

- UMS $+2 \mathrm{D}$

- UMS+3D

Figure10: Global transport success rates in the various nurseries for the years 2004, 2008 and 2011. The four velocity fields considered in the model are shown: the full velocity field $U_{M F S}+U_{2 D}+U_{3 D}, U_{M F S}, U_{M F S}$ $+U_{2 D}$ and $U_{M F S}+U_{3 D}$. Only larvae released in June are considered. 


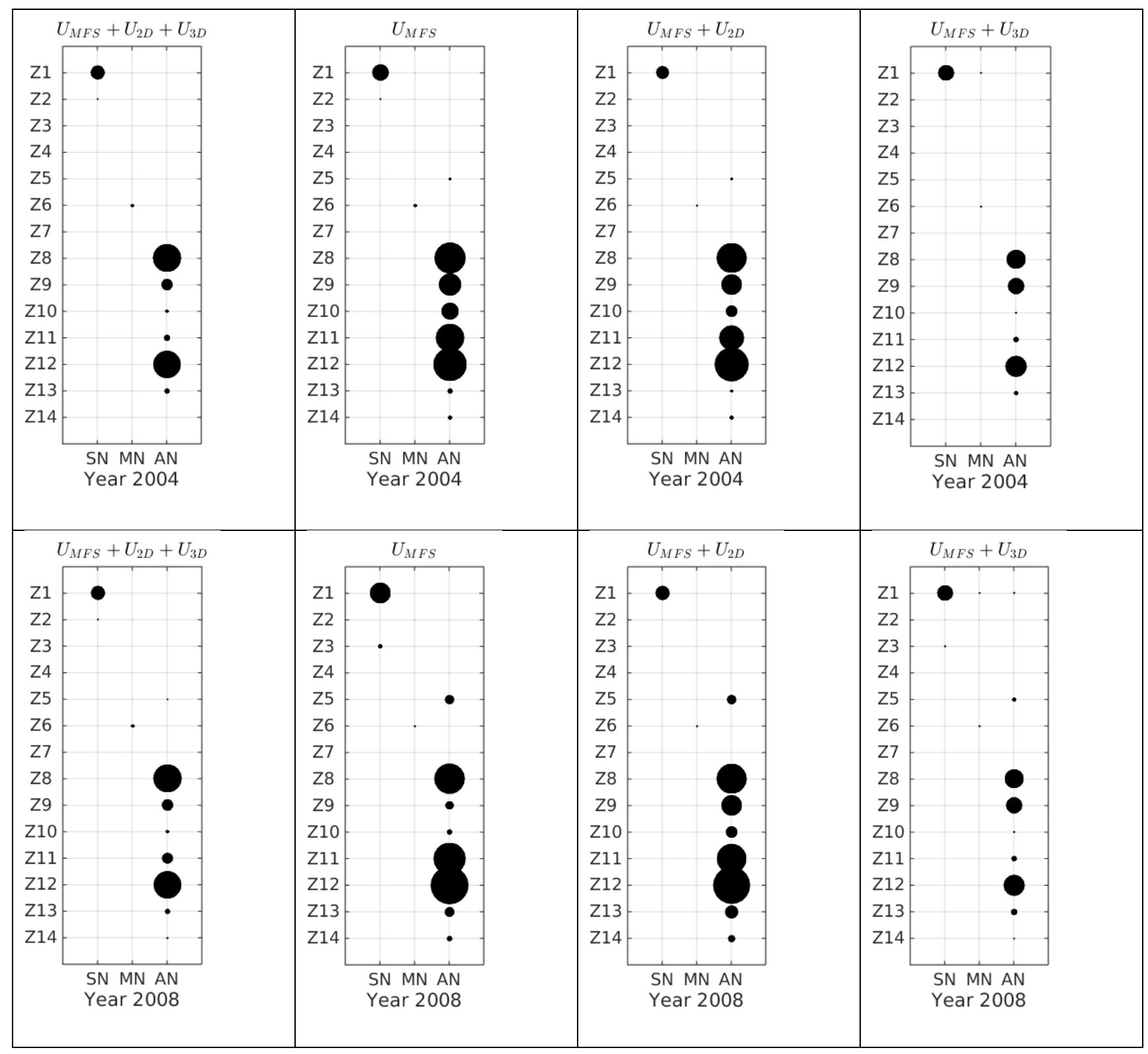

Figure 11: Connectivity matrices for transport success in the years 2004 and 2008 in the case of full velocity field $U_{M F S}+U_{2 D}+U_{3 D}$ (first column), $U_{M F S}$ (second column), $U_{M F S}+U_{2 D}$ (third column) and $U_{M F S}+U_{3 D}$ (fourth column). Only larvae released in June are considered. Circle area is proportional to the magnitude of transport success. 


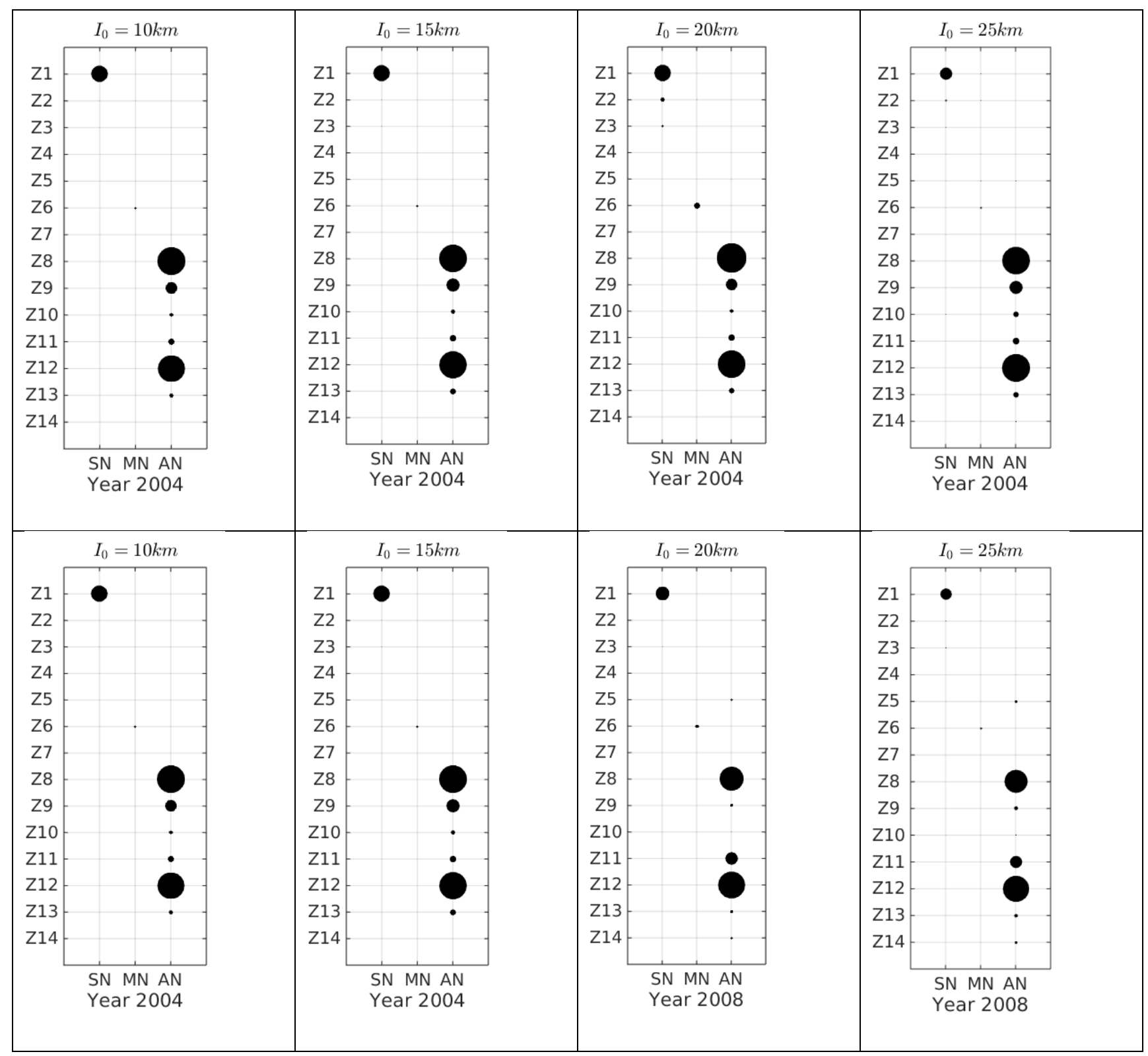

Figure 12: Connectivity matrices for transport success in the years 2004 and 2008 in the case of full velocity field $U_{M F S}+U_{2 D}+U_{3 D}$ for various values of the parameter $I_{0}$ in the velocity field $U_{2 D}$. Only larvae released in June are considered. Circle area is proportional to the magnitude of transport success. 


\begin{tabular}{|l|l|l|l|l|l|}
\hline \multicolumn{2}{|c|}{$A_{0}=0.001 \mathrm{~m} / \mathrm{s}$} \\
$\mathrm{Znn}$
\end{tabular}

Figure 13: Connectivity matrices for transport success in the years 2004 and 2008 in the case of full velocity field $U_{M F s}+U_{2 D}+U_{3 D}$ for various values of the parameter $A_{0}$ in the velocity field $U_{2 D}$. Only larvae released in June are considered. Circle area is proportional to the magnitude of transport success. 


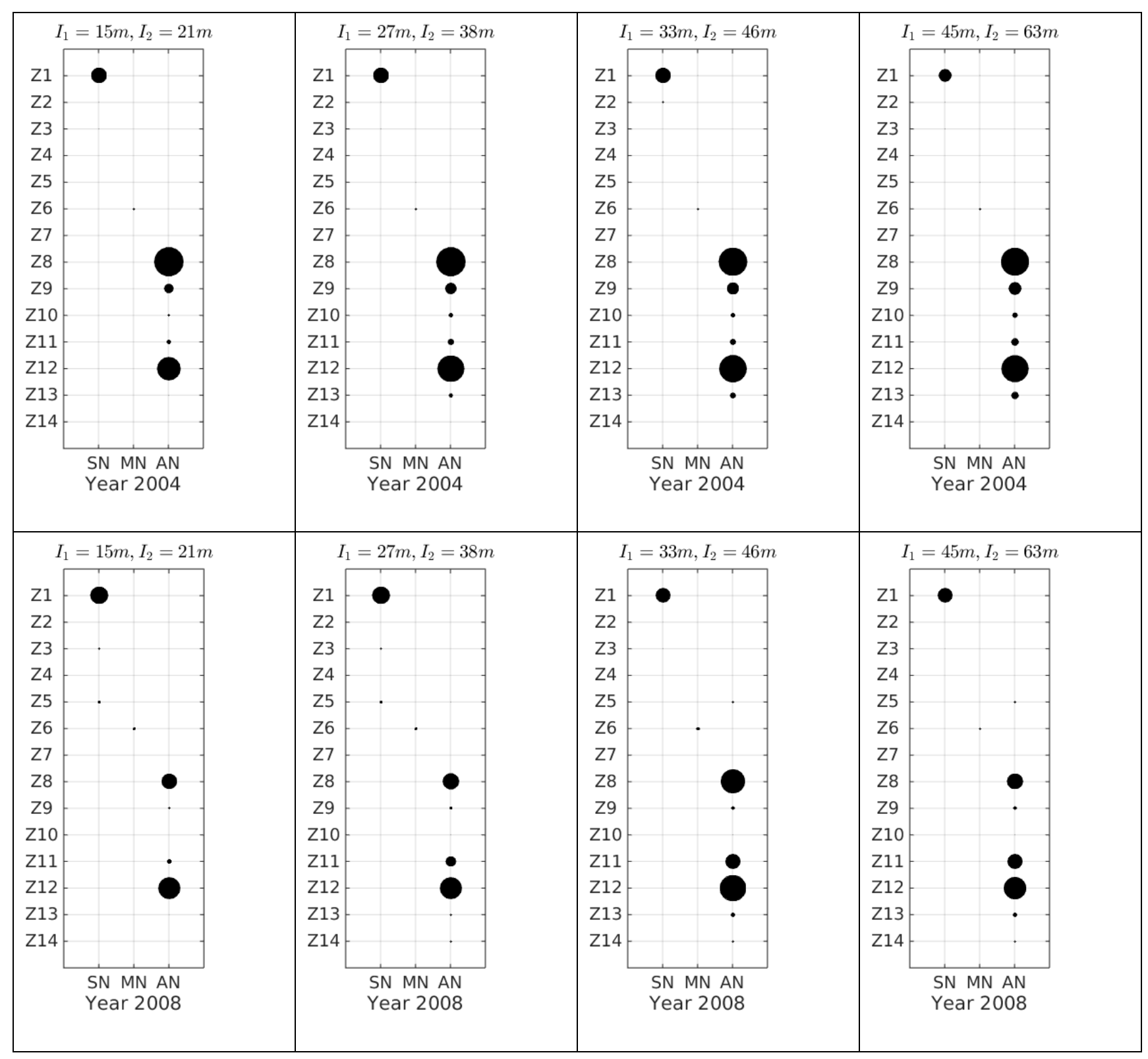

Figure 14: Connectivity matrices for transport success in the years 2004 and 2008 in the case of full velocity field $U_{M F S}+U_{2 D}+U_{3 D}$ for various values of the parameter $I_{0}$ in the velocity field $U_{2 D}$. Only larvae released in June are considered. Circle area is proportional to the magnitude of transport success. 


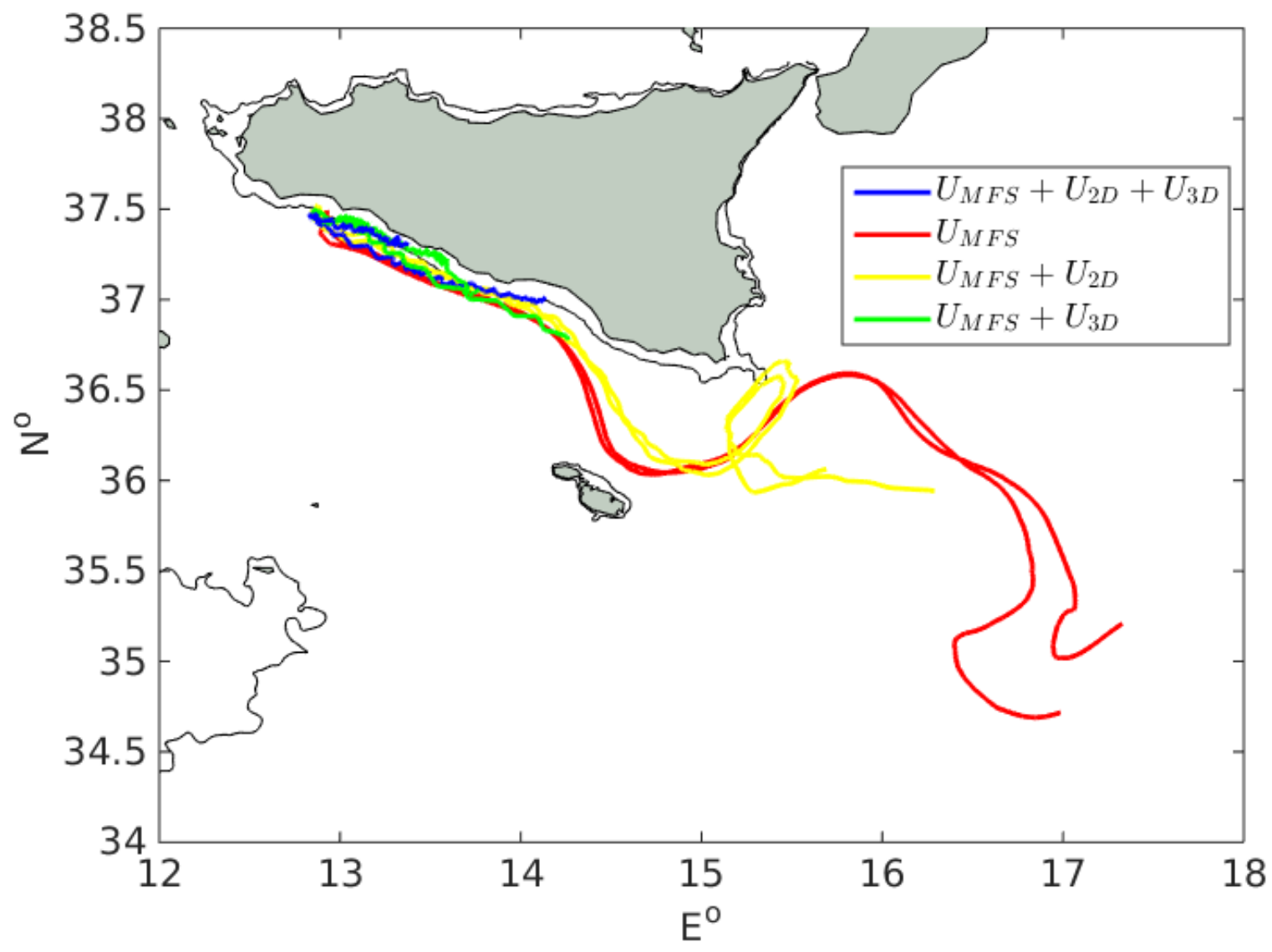

Figure 15: : Selected 45-days particle-paths starting from $\mathrm{Zm1}$, with particles released in all cases in the same position at June 15, 2004. 


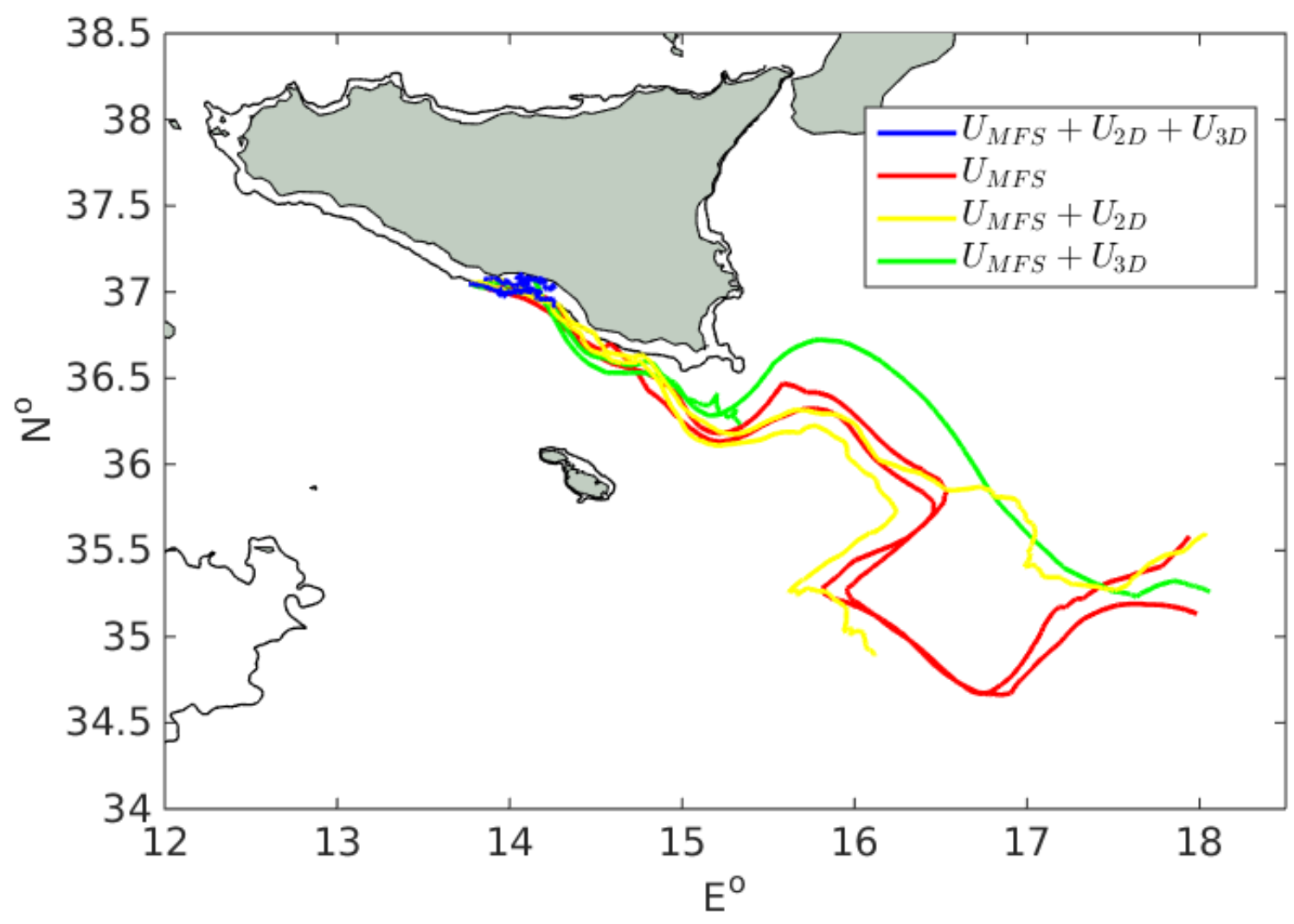

Figure 16: Selected 45-days particle-paths starting from $\mathrm{Zm2}$, with particles released in all cases in the same position at June 15, 2004. 


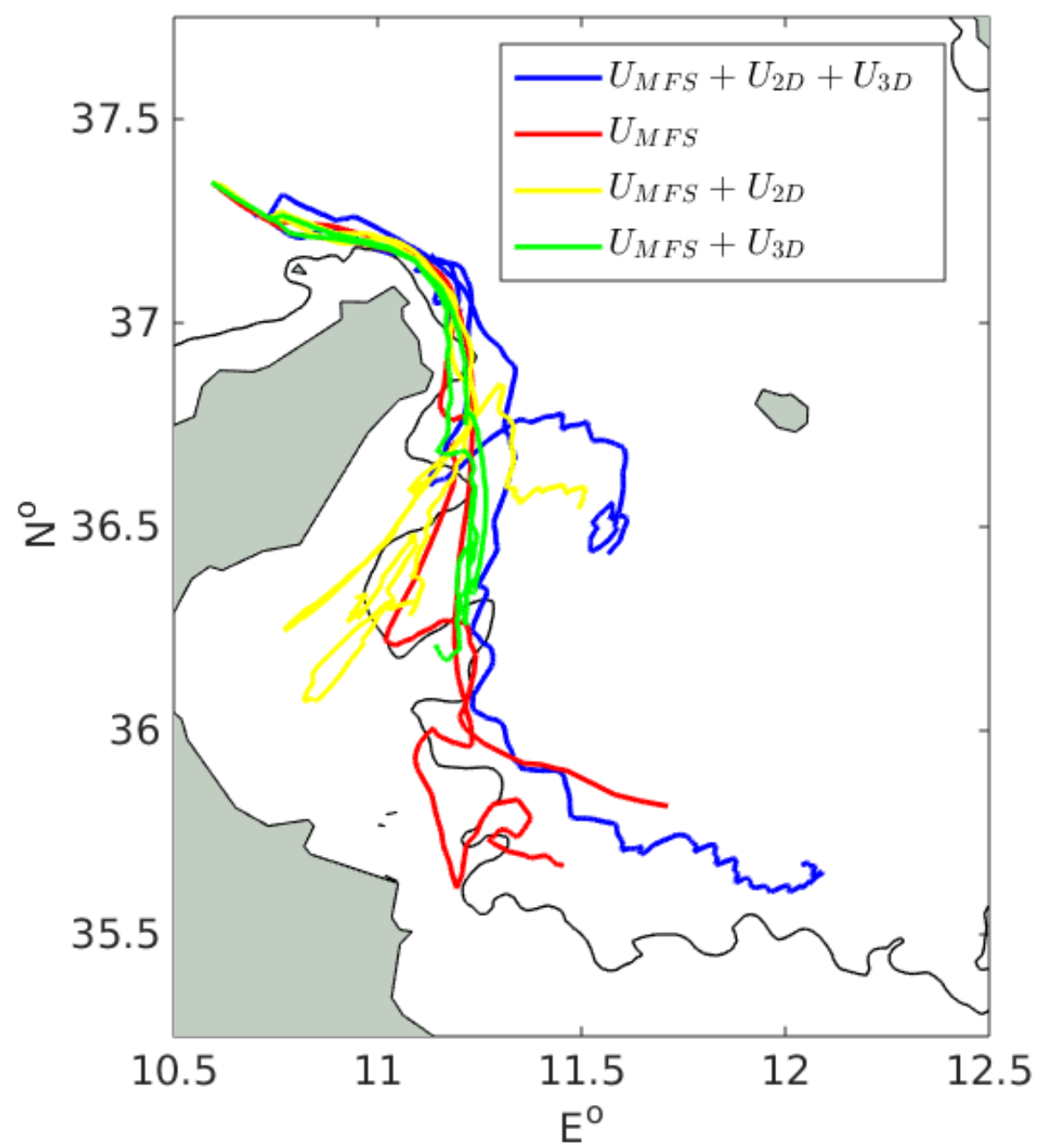

Figure 17: Selected 45-days particle-paths starting from $\mathrm{Zm9}$, with particles released in all cases in the same position at June 15, 2004. 
